\title{
Space-Time Variational Multiscale Isogeometric Analysis of a tsunami-shelter vertical-axis wind turbine
}

\author{
Yuto Otoguro $^{1} \cdot$ Hiroki Mochizuki ${ }^{2} \cdot$ Kenji Takizawa $^{2} \cdot$ Tayfun E. Tezduyar $^{3,4}$
}

Received: 16 July 2020 / Accepted: 17 August 2020 / Published online: 31 August 2020

(c) The Author(s) 2020

\begin{abstract}
We present computational flow analysis of a vertical-axis wind turbine (VAWT) that has been proposed to also serve as a tsunami shelter. In addition to the three-blade rotor, the turbine has four support columns at the periphery. The columns support the turbine rotor and the shelter. Computational challenges encountered in flow analysis of wind turbines in general include accurate representation of the turbine geometry, multiscale unsteady flow, and moving-boundary flow associated with the rotor motion. The tsunami-shelter VAWT, because of its rather high geometric complexity, poses the additional challenge of reaching high accuracy in turbine-geometry representation and flow solution when the geometry is so complex. We address the challenges with a space-time (ST) computational method that integrates three special ST methods around the core, ST Variational Multiscale (ST-VMS) method, and mesh generation and improvement methods. The three special methods are the ST Slip Interface (ST-SI) method, ST Isogeometric Analysis (ST-IGA), and the ST/NURBS Mesh Update Method (STNMUM). The ST-discretization feature of the integrated method provides higher-order accuracy compared to standard discretization methods. The VMS feature addresses the computational challenges associated with the multiscale nature of the unsteady flow. The moving-mesh feature of the ST framework enables high-resolution computation near the blades. The ST-SI enables moving-mesh computation of the spinning rotor. The mesh covering the rotor spins with it, and the SI between the spinning mesh and the rest of the mesh accurately connects the two sides of the solution. The ST-IGA enables more accurate representation of the blade and other turbine geometries and increased accuracy in the flow solution. The STNMUM enables exact representation of the mesh rotation. A general-purpose NURBS mesh generation method makes it easier to deal with the complex turbine geometry. The quality of the mesh generated with this method is improved with a mesh relaxation method based on fiber-reinforced hyperelasticity and optimized zero-stress state. We present computations for the 2D and 3D cases. The computations show the effectiveness of our ST and mesh generation and relaxation methods in flow analysis of the tsunami-shelter VAWT.
\end{abstract}

Keywords Vertical-axis wind turbine $\cdot$ Tsunami shelter $\cdot$ Space-Time Variational Multiscale method $\cdot$ ST-VMS $\cdot$ ST Slip Interface method $\cdot$ ST Isogeometric Analysis $\cdot$ NURBS mesh generation $\cdot$ Mesh relaxation

\section{Introduction}

Kenji Takizawa

Kenji.Takizawa@tafsm.org

Yuto Otoguro

Yuto.Otoguro@tafsm.org

Tayfun E. Tezduyar

tezduyar@tafsm.org

1 Department of Mechanical Engineering, Faculty of Science and Technology, Tokyo University of Science, 2641 Yamazaki, Noda, Chiba-ken 278-8510, Japan

2 Department of Modern Mechanical Engineering, Waseda University, 3-4-1 Ookubo, Shinjuku-ku, Tokyo 169-8555, Japan
We address the computational challenges encountered in and present results from flow analysis of a vertical-axis wind turbine (VAWT) that has been proposed to also serve as a tsunami shelter. The VAWT model is based on "Life tower" [1]. In addition to the three-blade rotor, the turbine has four support columns at the periphery. The columns support the

3 Mechanical Engineering, Rice University, MS 321, 6100 Main Street, Houston, TX 77005, USA

4 Faculty of Science and Engineering, Waseda University, 3-4-1 Ookubo, Shinjuku-ku, Tokyo 169-8555, Japan 
turbine rotor and the shelter. The challenges encountered in computational flow analysis of wind turbines in general include accurate representation of the turbine geometry, multiscale unsteady flow, and moving-boundary flow associated with the rotor motion. The tsunami-shelter VAWT, because of its rather high geometric complexity, poses the additional challenge of reaching high accuracy in turbine-geometry representation and flow solution when the geometry is so complex.

The computational challenges encountered in flow analysis of turbines in a more general context have been addressed also by other researchers. The approaches are quite diverse, such as using a single blade with spatially-periodic boundary conditions (see, e.g., [2-9]), which is more traditional, and "sliding interfaces" (see, e.g., [10-15]), which is more recent.

We address the challenges with a space-time (ST) computational method that integrates three special ST methods around a core ST method and mesh-related methods. The core method is the ST Variational Multiscale (ST-VMS) method [16-18], which subsumes its precursor "ST-SUPS" (see Sect. 1.1). The three special methods are the ST Slip Interface (ST-SI) method [19,20], ST Isogeometric Analysis (ST-IGA) [16,21,22], and the ST/NURBS Mesh Update Method (STNMUM) [21,23-25]. The mesh-related methods are a general-purpose NURBS mesh generation method $[26,27]$ and a mesh relaxation method [28] based on fiberreinforced hyperelasticity and optimized zero-stress state (ZSS).

The ST-discretization feature of the integrated method provides higher-order accuracy compared to standard discretization methods. The VMS feature addresses the computational challenges associated with the multiscale nature of the unsteady flow. The moving-mesh feature of the ST framework enables high-resolution computation near the blades. The ST-SI enables moving-mesh computation of the spinning rotor. The mesh covering the rotor spins with it, and the SI between the spinning mesh and the rest of the mesh accurately connects the two sides of the solution. The STIGA enables more accurate representation of the blade and other turbine geometries and increased accuracy in the flow solution. The STNMUM enables exact representation of the mesh rotation. The general-purpose NURBS mesh generation method makes it easier to deal with the complex turbine geometry. The quality of the mesh generated with this method is improved with the mesh relaxation method.

The first flow computations for the tsunami-shelter VAWT were presented in [19], in the context of finite element discretization, as test computations with 2D and 3D models to show how the ST-SI method, introduced in the paper, worked. Preliminary test computations with isogeometric discretization were presented in [29] for the 2D model and in [30] for both the $2 \mathrm{D}$ and $3 \mathrm{D}$ models.

\subsection{ST-VMS and ST-SUPS}

The Deforming-Spatial-Domain/Stabilized ST (DSD/SST) method [31-33] was introduced for computation of flows with moving boundaries and interfaces (MBI), including fluid-structure interaction (FSI). In MBI computations the DSD/SST functions as a moving-mesh method. Moving the fluid mechanics mesh to follow an interface enables mesh resolution control near the interface and, consequently, highresolution boundary-layer representation near fluid-solid interfaces. Because the stabilization components of the original DSD/SST are the Streamline-Upwind/Petrov-Galerkin (SUPG) [34] and Pressure-Stabilizing/Petrov-Galerkin ( $\underline{\mathrm{PS}} \mathrm{PG}$ ) [31] stabilizations, it is now called "ST-SUPS." The ST-VMS is the VMS version of the DSD/SST. The VMS components of the ST-VMS are from the residual-based VMS (RBVMS) method [35-38]. The ST-VMS has two more stabilization terms beyond those in the ST-SUPS, and the additional terms give the method better turbulence modeling features. The ST-SUPS and ST-VMS, because of the higher-order accuracy of the ST framework (see [16,17]), are desirable also in computations without MBI.

As a moving-mesh method, the DSD/SST is an alternative to the Arbitrary Lagrangian-Eulerian (ALE) method, which is older (see, for example, [39]) and more commonly used. The ALE-VMS method [40-46] is the VMS version of the ALE. It succeeded the ST-SUPS and ALE-SUPS [47] and preceded the ST-VMS. To increase their scope and accuracy, the ALE-VMS and RBVMS are often supplemented with special methods, such as those for weaklyenforced Dirichlet boundary conditions [48-50], "sliding interfaces" [51,52], and backflow stabilization [53]. The ALE-SUPS, RBVMS and ALE-VMS have been applied to many classes of FSI, MBI and fluid mechanics problems. The classes of problems include ram-air parachute FSI [47], wind-turbine aerodynamics and FSI [10-15,5460], more specifically, VAWTs $[12,13,61,62]$, floating wind turbines [63], wind turbines in atmospheric boundary layers $[12,13,29,30,60,64]$, and fatigue damage in wind-turbine blades [65], patient-specific cardiovascular fluid mechanics and FSI [40,66-71], biomedical-device FSI [72-79], ship hydrodynamics with free-surface flow and fluid-object interaction [80,81], hydrodynamics and FSI of a hydraulic arresting gear $[82,83]$, hydrodynamics of tidal-stream turbines with free-surface flow [84], passive-morphing FSI in turbomachinery [8], bioinspired FSI for marine propulsion [85, 86], bridge aerodynamics and fluid-object interaction [8789], and mixed ALE-VMS/Immersogeometric computations [75-77,90,91] in the framework of the Fluid-Solid InterfaceTracking/Interface-Capturing Technique [92]. Recent advances in stabilized and multiscale methods may be found for stratified incompressible flows in [93], for divergenceconforming discretizations of incompressible flows in [94], 
and for compressible flows with emphasis on gas-turbine modeling in [95].

The ST-SUPS and ST-VMS have also been applied to many classes of FSI, MBI and fluid mechanics problems (see [96] for a comprehensive summary of the work prior to July 2018). The classes of problems include spacecraft parachute analysis for the landing-stage parachutes [43,97-100], cover-separation parachutes [101] and the drogue parachutes [102-104], wind-turbine aerodynamics for horizontal-axis wind-turbine (HAWT) rotors [10,43, 105,106], full HAWTs $[11,25,107,108]$ and VAWTs [1215,19], flapping-wing aerodynamics for an actual locust [21,23,43,109], bioinspired MAVs [24,107,108,110] and wing-clapping [111,112], blood flow analysis of cerebral aneurysms [107,113], stent-blocked aneurysms [113-115], aortas [78,79,116-120], heart valves [78,79,108,111,118, 120-125] and coronary arteries in motion [126], spacecraft aerodynamics [101,127], thermo-fluid analysis of ground vehicles and their tires [18,29,30,122], thermo-fluid analysis of disk brakes [20], flow-driven string dynamics in turbomachinery $[14,15,128-130]$, flow analysis of turbocharger turbines [22,26,27,131,132], flow around tires with road contact and deformation [122,133-136], fluid films [136,137], ramair parachutes $[29,30,138]$, and compressible-flow spacecraft parachute aerodynamics [139,140].

The ST-SUPS, ALE-SUPS, RBVMS, ALE-VMS and STVMS all have some embedded stabilization parameters that play a significant role (see [43]). These parameters involve a measure of the local length scale (also known as "element length") and other parameters such as the element Reynolds and Courant numbers. There are many ways of defining the stabilization parameters. Some of the newer options for the stabilization parameters used with the SUPS and VMS can be found in $[18,19,21,25,106,135,141-145]$. Some of the earlier stabilization parameters used with the SUPS and VMS were also used in computations with other SUPG-like methods, such as the computations reported in [2,3,5,7-9,146-153]. We will specify which ones we use here in Appendix A.1 and when we describe the computations in Sect. 4.

\subsection{ST-SI}

The ST-SI was introduced in [19], in the context of incompressible-flow equations, to retain the desirable moving-mesh features of the ST-VMS and ST-SUPS in computations involving spinning solid surfaces, such as a turbine rotor. The mesh covering the spinning surface spins with it, retaining the high-resolution representation of the boundary layers, while the mesh on the other side of the SI remains unaffected. This is accomplished by adding to the ST-VMS formulation interface terms similar to those in the ALE-SI [51,52]. The interface terms account for the compatibility conditions for the velocity and stress at the SI, accurately connecting the two sides of the solution. An ST-SI version where the SI is between fluid and solid domains was also presented in [19]. The SI in that case is a "fluid-solid SI" rather than a standard "fluid-fluid SI" and enables weak enforcement of the Dirichlet boundary conditions for the fluid. The ST-SI introduced in [20] for the coupled incompressible-flow and thermaltransport equations retains the high-resolution representation of the thermo-fluid boundary layers near spinning solid surfaces. These ST-SI methods have been applied to aerodynamic analysis of VAWTs [12-15,19], thermo-fluid analysis of disk brakes [20], flow-driven string dynamics in turbomachinery [14,15,128-130], flow analysis of turbocharger turbines [22,26,27,131,132], flow around tires with road contact and deformation [122,133-136], fluid films [136,137], aerodynamic analysis of ram-air parachutes [29,30,138], and flow analysis of heart valves [78,79,118,123-125] and ventricle-valve-aorta sequences [120].

In the ST-SI version presented in [19] the SI is between a thin porous structure and the fluid on its two sides. This enables dealing with the porosity in a fashion consistent with how the standard fluid-fluid SIs are dealt with and how the Dirichlet conditions are enforced weakly with fluid-solid SIs. This version also enables handling thin structures that have T-junctions. This method has been applied to incompressibleflow aerodynamic analysis of ram-air parachutes with fabric porosity [29,30,138]. The compressible-flow ST-SI methods were introduced in [139], including the version where the SI is between a thin porous structure and the fluid on its two sides. Compressible-flow porosity models were also introduced in [139]. These, together with the compressibleflow ST SUPG method [154], extended the ST computational analysis range to compressible-flow aerodynamics of parachutes with fabric and geometric porosities. That enabled ST computational flow analysis of the Orion spacecraft drogue parachute in the compressible-flow regime $[139,140]$.

\subsection{ST-IGA and STNMUM}

The success with IGA basis functions in space $[40,51,66,155]$ motivated the integration of the ST methods with isogeometric discretization, which is broadly called "ST-IGA." The ST-IGA was introduced in [16]. Computations with the STVMS and ST-IGA were first reported in [16] in a 2D context, with IGA basis functions in space for flow past an airfoil, and in both space and time for the advection equation. Using higher-order basis functions in time enables deriving full benefit from using higher-order basis functions in space. This was demonstrated with the stability and accuracy analysis given in [16] for the advection equation.

The ST-IGA with IGA basis functions in time enables a more accurate representation of the motion of the solid surfaces and a mesh motion consistent with that. This was pointed out in $[16,17]$ and demonstrated in $[21,23,24]$. It also 
enables more efficient temporal representation of the motion and deformation of the volume meshes, and more efficient remeshing. These motivated the development of the STNMUM [21,23,24], with the name coined in [25]. The STNMUM has a wide scope that includes spinning solid surfaces. With the spinning motion represented by quadratic NURBS in time, and with sufficient number of temporal patches for a full rotation, the circular paths are represented exactly. A "secondary mapping" $[16,17,21,43]$ enables also specifying a constant angular velocity for invariant speeds along the circular paths. The ST framework and NURBS in time also enable, with the "ST-C" method, extracting a continuous representation from the computed data and, in large-scale computations, efficient data compression $[18,20,122,128$ 130,156]. The STNMUM and the ST-IGA with IGA basis functions in time have been used in many $3 \mathrm{D}$ computations. The classes of problems solved are flapping-wing aerodynamics for an actual locust [21,23,43,109], bioinspired MAVs $[24,107,108,110]$ and wing-clapping [111,112], separation aerodynamics of spacecraft [101], aerodynamics of horizontal-axis $[11,25,107,108]$ and vertical-axis $[12-15,19]$ wind-turbines, thermo-fluid analysis of ground vehicles and their tires $[18,29,122]$, thermo-fluid analysis of disk brakes [20], flow-driven string dynamics in turbomachinery $[14,15,128-130]$, flow analysis of turbocharger turbines $[22,26,27,131,132]$, and flow analysis of coronary arteries in motion [126].

The ST-IGA with IGA basis functions in space enables more accurate representation of the geometry and increased accuracy in the flow solution. It accomplishes that with fewer control points, and consequently with larger effective element sizes. That in turn enables using larger time-step sizes while keeping the Courant number at a desirable level for good accuracy. It has been used in ST computational flow analysis of turbocharger turbines [22,26,27,131,132], flow-driven string dynamics in turbomachinery [14,15,129, 130], ram-air parachutes $[29,30,138]$, spacecraft parachutes [140], aortas [78,118,119], heart valves [78,79,118,123125], ventricle-valve-aorta sequences [120], coronary arteries in motion [126], tires with road contact and deformation [134-136], and fluid films [136,137]. The image-based arterial geometries used in patient-specific arterial FSI computations do not come from the ZSS of the artery. A number of methods $[41,43,157-166]$ have been proposed for estimating the ZSS required in the computations. Using IGA basis functions in space is now a key part of some of the newest ZSS estimation methods [78,164-167] and related shell analysis [168]. The IGA has also been successfully applied to the structural analysis of wind turbine blades [169-173]

\subsection{General-purpose NURBS mesh generation method}

To make the ST-IGA use, and in a wider context the IGA use, even more practical in computational flow analysis with complex geometries, NURBS volume mesh generation needs to be easier and more automated. To that end, a generalpurpose NURBS mesh generation method was introduced in [26]. The method is based on multi-block-structured mesh generation with existing techniques, projection of that mesh to a NURBS mesh made of patches that correspond to the blocks, and recovery of the original model surfaces. The recovery of the original surfaces is to the extent they are suitable for accurate and robust fluid mechanics computations. The method is expected to retain the refinement distribution and element quality of the multi-block-structured mesh that we start with. Because there are ample good techniques and software for generating multi-block-structured meshes, the method makes general-purpose mesh generation relatively easy. Mesh-quality performance studies for 2D and 3D meshes, including those for complex models, were presented in [27]. A test computation for a turbocharger turbine and exhaust manifold was also presented in [27], with a more detailed computation in [131], and with additional computational analysis in [132]. The mesh generation method was used also in the pump-flow analysis part of the flow-driven string dynamics presented in $[14,15,130]$. The performance studies and test computations demonstrated that the generalpurpose NURBS mesh generation method makes the IGA use in fluid mechanics computations even more practical.

\subsection{ST-SI-IGA}

An SI provides mesh generation flexibility in a general context by accurately connecting the two sides of the solution computed over nonmatching meshes. This type of mesh generation flexibility is especially valuable in complex-geometry flow computations with isogeometric discretization, removing the matching requirement between the NURBS patches without loss of accuracy. This feature was used in the flow analysis of heart valves $[78,79,118,123-125]$, ventriclevalve-aorta sequences [120], turbocharger turbines [22,26, 27,131,132], spacecraft parachute compressible-flow analysis [140], and flow around tires with road contact and deformation $[135,136]$. It is used also in the VAWT flow analysis presented here.

\subsection{Mesh relaxation based on fiber-reinforced hyperelasticity and optimized ZSS}

Mesh relaxation and mesh moving methods based on fiberreinforced hyperelasticity and optimized ZSS were introduced in [28]. The methods have been developed targeting 
isogeometric discretization but are also applicable to finite element discretization. The objective of the mesh relaxation is to improve the quality of the mesh after its initial creation and to have an equilibrium state with the optimized ZSS, boundary conditions and the constitutive law. The constitutive models and parameters can be defined individually for the elements or mesh regions. For more on the method, see [28].

\subsection{Computations presented}

We present computations for the 2D and 3D cases. In the 2D case, we present computations for three different meshes, two different time-step sizes, and two different tip-speed ratios. In the 3D case, we compute with one of the combinations of the $2 \mathrm{D}$ case and compare the $2 \mathrm{D}$ and $3 \mathrm{D}$ results.

\subsection{Outline of the remaining sections}

In Sect. 2, for completeness, we describe the ST-VMS and ST-SI. The tsunami-shelter VAWT model is described in Sect. 3. We present the computations in Sect. 4, and give the concluding remarks in Sect. 5. The stabilization parameters used in the ST-VMS and ST-SI are given in Appendix A.

\section{ST-VMS and ST-SI}

For completeness, we include, mostly from $[19,133]$, the STVMS and ST-SI methods.

\subsection{ST-VMS}

The ST-VMS is given as

$$
\begin{aligned}
& \int_{Q_{n}} \mathbf{w}^{h} \cdot \rho\left(\frac{\partial \mathbf{u}^{h}}{\partial t}+\mathbf{u}^{h} \cdot \nabla_{\left.\mathbf{u}^{h}-\mathbf{f}^{h}\right) \mathrm{d} Q}\right. \\
& +\int_{Q_{n}} \boldsymbol{\varepsilon}\left(\mathbf{w}^{h}\right): \boldsymbol{\sigma}^{h} \mathrm{~d} Q-\int_{\left(P_{n}\right)_{\mathrm{h}}} \mathbf{w}^{h} \cdot \mathbf{h}^{h} \mathrm{~d} P \\
& +\int_{Q_{n}} q^{h} \boldsymbol{\nabla} \cdot \mathbf{u}^{h} \mathrm{~d} Q+\int_{\Omega_{n}}\left(\mathbf{w}^{h}\right)_{n}^{+} \cdot \rho\left(\left(\mathbf{u}^{h}\right)_{n}^{+}-\left(\mathbf{u}^{h}\right)_{n}^{-}\right) \mathrm{d} \Omega \\
& +\sum_{e=1}^{\left(n_{\mathrm{el}}\right)_{n}} \int_{Q_{n}^{e}} \frac{\tau_{\mathrm{SUPS}}}{\rho}\left(\rho\left(\frac{\partial \mathbf{w}^{h}}{\partial t}+\mathbf{u}^{h} \cdot \nabla_{\mathbf{w}^{h}}\right)+\nabla q^{h}\right) \cdot \mathbf{r}_{\mathrm{M}}^{h} \mathrm{~d} Q \\
& +\sum_{e=1}^{\left(n_{\mathrm{el}}\right)_{n}} \int_{Q_{n}^{e}} v_{\mathrm{LSIC}} \boldsymbol{\nabla} \cdot \mathbf{w}^{h} \rho r_{\mathrm{C}}^{h} \mathrm{~d} Q \\
& \quad-\sum_{e=1}^{\left(n_{\mathrm{el}}\right)_{n}} \int_{Q_{n}^{e}} \tau_{\mathrm{SUPS}} \mathbf{w}^{h} \cdot\left(\mathbf{r}_{\mathrm{M}}^{h} \cdot \nabla \mathbf{u}^{h}\right) \mathrm{d} Q
\end{aligned}
$$

$$
-\sum_{e=1}^{\left(n_{\mathrm{el} 1}\right)_{n}} \int_{Q_{n}^{e}} \frac{\tau_{\mathrm{SUPS}}^{2}}{\rho} \mathbf{r}_{\mathrm{M}}^{h} \cdot\left(\nabla \mathbf{w}^{h}\right) \cdot \mathbf{r}_{\mathrm{M}}^{h} \mathrm{~d} Q
$$

$=0$,

where

$\mathbf{r}_{\mathrm{M}}^{h}=\rho\left(\frac{\partial \mathbf{u}^{h}}{\partial t}+\mathbf{u}^{h} \cdot \nabla \mathbf{u}^{h}-\mathbf{f}^{h}\right)-\nabla \cdot \boldsymbol{\sigma}^{h}$,

$r_{\mathrm{C}}^{h}=\nabla \cdot \mathbf{u}^{h}$

are the residuals of the momentum equation and incompressibility constraint. Here, $\rho, \mathbf{u}, p, \mathbf{f}$, and $\mathbf{h}$ are the density, velocity, pressure, body force, and the stress specified at the boundary. The stress tensor is defined as $\sigma=-p \mathbf{I}+2 \mu \varepsilon(\mathbf{u})$, where $\mathbf{I}$ is the identity tensor, $\mu=\rho v$ is the viscosity, $v$ is the kinematic viscosity, and $\varepsilon(\mathbf{u})=\left((\nabla \mathbf{u})+(\nabla \mathbf{u})^{T}\right) / 2$ is the strain-rate tensor. The test functions associated with the $\mathbf{u}$ and $p$ are $\mathbf{w}$ and $q$. A superscript " $h$ " indicates that the function is coming from a finite-dimensional space. The symbol $Q_{n}$ represents the ST slice between time levels $n$ and $n+1$, $\left(P_{n}\right)_{\mathrm{h}}$ is the part of the slice lateral boundary associated with the boundary condition $\mathbf{h}$, and $\Omega_{n}$ is the spatial domain at time level $n$. The superscript " $e$ " is the ST element counter, and $n_{\mathrm{el}}$ is the number of ST elements. The functions are discontinuous in time at each time level, and the superscripts "-" and "+" indicate the values of the functions just below and above the time level.

Remark 1 The ST-SUPS can be obtained from the ST-VMS by dropping the eighth and ninth integrations.

The stabilization parameters, $\tau_{\text {SUPS }}$ and $\nu_{\text {LSIC }}$, will be given in Appendix A.1.

\subsection{ST-SI}

In describing the ST-SI, labels "Side A" and "Side B" will represent the two sides of the SI. The ST-SI version of the formulation given by Eq. (1) includes added boundary terms corresponding to the SI. The boundary terms for the two sides are first added separately, using the test functions $\mathbf{w}_{\mathrm{A}}^{h}$ and $q_{\mathrm{A}}^{h}$ and $\mathbf{w}_{\mathrm{B}}^{h}$ and $q_{\mathrm{B}}^{h}$. Then, putting together the terms added to each side, the complete set of terms added becomes

$$
\begin{aligned}
& -\int_{\left(P_{n}\right)_{\mathrm{SI}}}\left(q_{\mathrm{B}}^{h} \mathbf{n}_{\mathrm{B}}-q_{\mathrm{A}}^{h} \mathbf{n}_{\mathrm{A}}\right) \cdot \frac{1}{2}\left(\mathbf{u}_{\mathrm{B}}^{h}-\mathbf{u}_{\mathrm{A}}^{h}\right) \mathrm{d} P \\
& -\int_{\left(P_{n}\right)_{\mathrm{SI}}} \rho \mathbf{w}_{\mathrm{B}}^{h} \cdot \frac{1}{2}\left(\left(\mathcal{F}_{\mathrm{B}}^{h}-\left|\mathcal{F}_{\mathrm{B}}^{h}\right|\right) \mathbf{u}_{\mathrm{B}}^{h}-\left(\mathcal{F}_{\mathrm{B}}^{h}-\left|\mathcal{F}_{\mathrm{B}}^{h}\right|\right) \mathbf{u}_{\mathrm{A}}^{h}\right) \mathrm{d} P \\
& -\int_{\left(P_{n}\right)_{\mathrm{SI}}} \rho \mathbf{w}_{\mathrm{A}}^{h} \cdot \frac{1}{2}\left(\left(\mathcal{F}_{\mathrm{A}}^{h}-\left|\mathcal{F}_{\mathrm{A}}^{h}\right|\right) \mathbf{u}_{\mathrm{A}}^{h}-\left(\mathcal{F}_{\mathrm{A}}^{h}-\left|\mathcal{F}_{\mathrm{A}}^{h}\right|\right) \mathbf{u}_{\mathrm{B}}^{h}\right) \mathrm{d} P \\
& +\int_{\left(P_{n}\right)_{\mathrm{SI}}}\left(\mathbf{n}_{\mathrm{B}} \cdot \mathbf{w}_{\mathrm{B}}^{h}+\mathbf{n}_{\mathrm{A}} \cdot \mathbf{w}_{\mathrm{A}}^{h}\right) \frac{1}{2}\left(p_{\mathrm{B}}^{h}+p_{\mathrm{A}}^{h}\right) \mathrm{d} P
\end{aligned}
$$




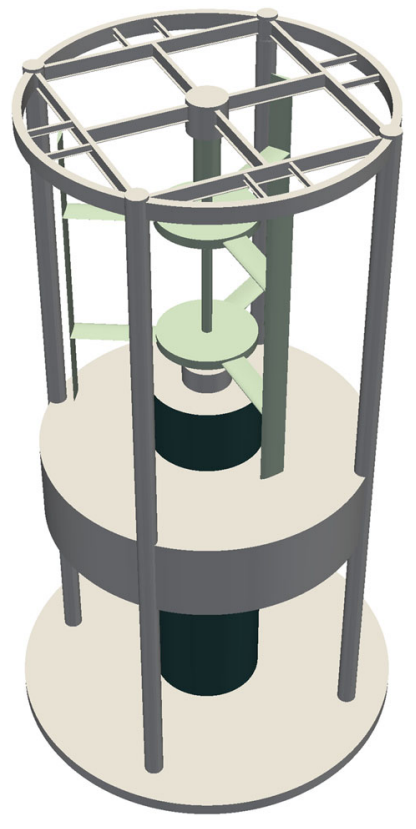

Fig. 1 Tsunami-shelter VAWT model. The disk-shaped structure just below the rotor is the shelter. The four columns at the periphery support the turbine rotor and the shelter

$$
\begin{aligned}
& -\int_{\left(P_{n}\right)_{\mathrm{SI}}}\left(\mathbf{w}_{\mathrm{B}}^{h}-\mathbf{w}_{\mathrm{A}}^{h}\right) \cdot\left(\hat{\mathbf{n}}_{\mathrm{B}} \cdot \mu\left(\varepsilon\left(\mathbf{u}_{\mathrm{B}}^{h}\right)+\varepsilon\left(\mathbf{u}_{\mathrm{A}}^{h}\right)\right)\right) \mathrm{d} P \\
& -\gamma \int_{\left(P_{n}\right)_{\mathrm{SI}}} \hat{\mathbf{n}}_{\mathrm{B}} \cdot \mu\left(\varepsilon\left(\mathbf{w}_{\mathrm{B}}^{h}\right)+\varepsilon\left(\mathbf{w}_{\mathrm{A}}^{h}\right)\right) \cdot\left(\mathbf{u}_{\mathrm{B}}^{h}-\mathbf{u}_{\mathrm{A}}^{h}\right) \mathrm{d} P \\
& +\int_{\left(P_{n}\right)_{\mathrm{SI}}} \frac{\mu C}{h}\left(\mathbf{w}_{\mathrm{B}}^{h}-\mathbf{w}_{\mathrm{A}}^{h}\right) \cdot\left(\mathbf{u}_{\mathrm{B}}^{h}-\mathbf{u}_{\mathrm{A}}^{h}\right) \mathrm{d} P,
\end{aligned}
$$

where

$$
\begin{aligned}
& \mathcal{F}_{\mathrm{B}}^{h}=\mathbf{n}_{\mathrm{B}} \cdot\left(\mathbf{u}_{\mathrm{B}}^{h}-\mathbf{v}_{\mathrm{B}}^{h}\right), \\
& \mathcal{F}_{\mathrm{A}}^{h}=\mathbf{n}_{\mathrm{A}} \cdot\left(\mathbf{u}_{\mathrm{A}}^{h}-\mathbf{v}_{\mathrm{A}}^{h}\right), \\
& \hat{\mathbf{n}}_{\mathrm{B}}=\frac{\mathbf{n}_{\mathrm{B}}-\mathbf{n}_{\mathrm{A}}}{\left\|\mathbf{n}_{\mathrm{B}}-\mathbf{n}_{\mathrm{A}}\right\|} .
\end{aligned}
$$

Here, $\left(P_{n}\right)_{\mathrm{SI}}$ is the SI in the ST domain, $\mathbf{n}$ is the unit normal vector, $\mathbf{v}$ is the mesh velocity, $\gamma=1$, and $C$ is a nondimensional constant. The element length $h$ will be defined in Appendix A.2.

\section{Tsunami-shelter VAWT model}

Figure 1 shows the VAWT model, which has four support columns at the periphery. The model is based on "Life tower" [1]. The rotor diameter is $16 \mathrm{~m}$, and the machine height is $45 \mathrm{~m}$. The three blades are based on the NACA0015 airfoil, and the chord length and the blade height are $1.5 \mathrm{~m}$ and $18 \mathrm{~m}$. There are two connecting rods from the hub to each blade, and the blades are supported without any tilt with respect to

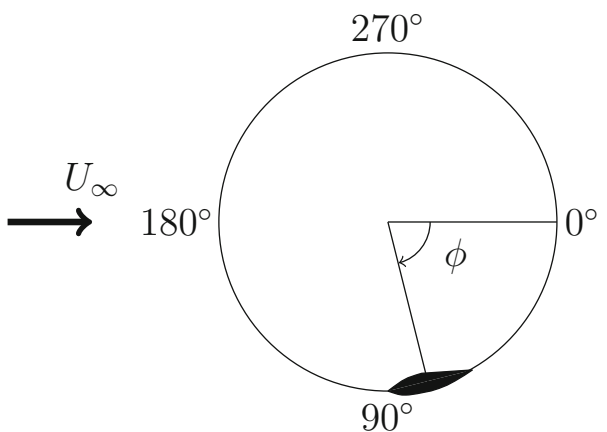

Fig. 2 Blade orientation as represented by the angle $\phi$

the tangent of the rotation path. The four support columns are cylindrical with circular cross-section, and they provide enough strength to support the rotor, which is estimated to weigh $3 \mathrm{t}$, and the shelter.

We carry out the computations at a constant free-stream velocity $U_{\infty}$ and with prescribed rotor motion at constant angular velocity. The rotation is clockwise viewed from the top. The air density and kinematic viscosity are $1.205 \mathrm{~kg} / \mathrm{m}^{3}$ and $1.511 \times 10^{-5} \mathrm{~m}^{2} / \mathrm{s}$. We extract from the computations the instantaneous power coefficient $C_{\mathrm{POW}}$, defined as

$C_{\mathrm{POW}}=\frac{P}{\frac{1}{2} \rho U_{\infty}^{3} A}$,

where $A$ and $P$ are the projected area of the wind turbine and the power generated. We report the power coefficient as a function of the blade orientation as represented by the angle $\phi$ seen in Fig. 2. With that orientation, the flow speed seen by a blade can be calculated as

$V=U_{\infty} \sqrt{1-2 \lambda \sin \phi+\lambda^{2}}$

where $\lambda$ is the tip-speed ratio (TSR). The symbol $T$ will denote the rotation cycle.

\section{Computations}

We present computations for the $2 \mathrm{D}$ and $3 \mathrm{D}$ cases. The computational-domain size in the wind direction is 62.5 times the rotor diameter, with a distance of 18.75 times the rotor diameter between the upstream boundary and the rotor center. In the cross-wind direction, the domain size is 37.5 times the rotor diameter. In the 3D case, the domain height is 10 times the rotor diameter. The mesh position is represented by quadratic NURBS in time. There are three patches that are $120^{\circ}$ each, and the secondary mapping introduced in [21] is used to achieve the constant angular velocity. We set $U_{\infty}=12.56 \mathrm{~m} / \mathrm{s}$. 


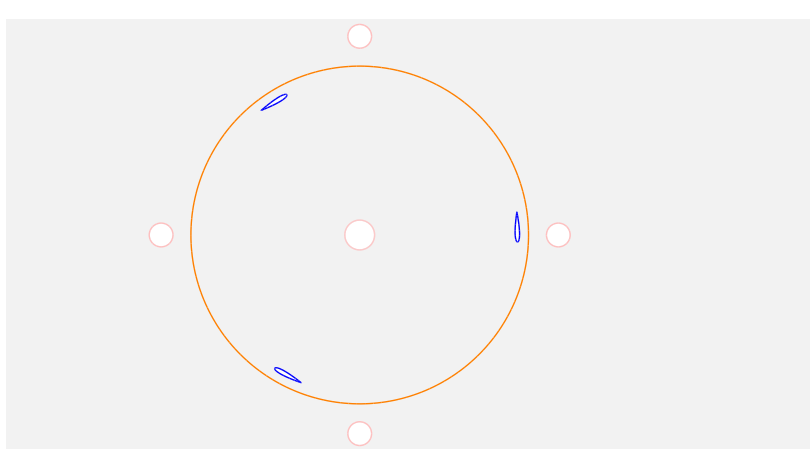

Fig. 3 2D case. Model geometry and SI

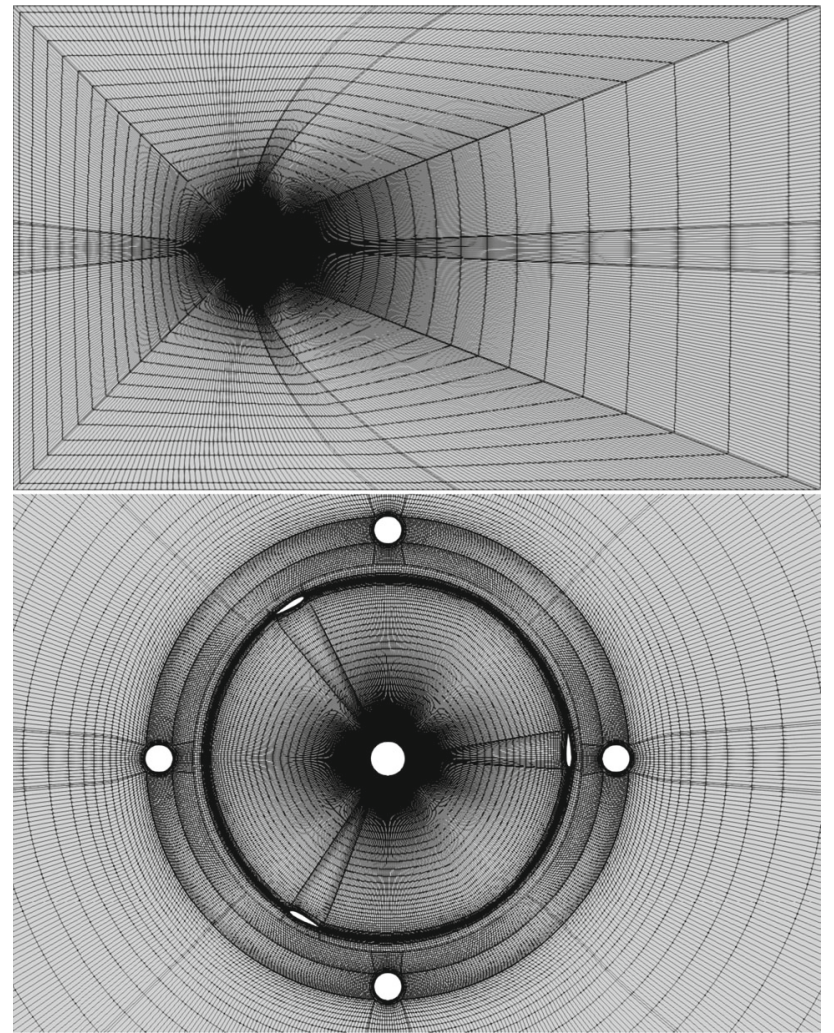

Fig. 4 2D case. Mesh 3 (control mesh)

In the $2 \mathrm{D}$ case, the time-step sizes used correspond to $\Delta \phi=1^{\circ}$ and $2^{\circ}$. In the 3D case, we use only one timestep size, and that corresponds to $\Delta \phi=1^{\circ}$. The number of nonlinear iterations per time step is 4 , and the number of GMRES iterations per nonlinear iteration is 200. The first two nonlinear iterations are based on the ST-SUPS, and the last two the ST-VMS. The stabilization parameters are those given by Eqs. (10)-(12) and (21)-(22). In the ST-SI (see Eq. (4)), we set $C=2$.
Table 12 D case. Number of control points $(n c)$ and elements (ne)

\begin{tabular}{lrr}
\hline Mesh & \multicolumn{1}{c}{$n c$} & \multicolumn{1}{c}{$n e$} \\
\hline Mesh 1 & 7510 & 5756 \\
Mesh 2 & 26,432 & 23,024 \\
Mesh 3 & 98,812 & 92,096 \\
\hline
\end{tabular}
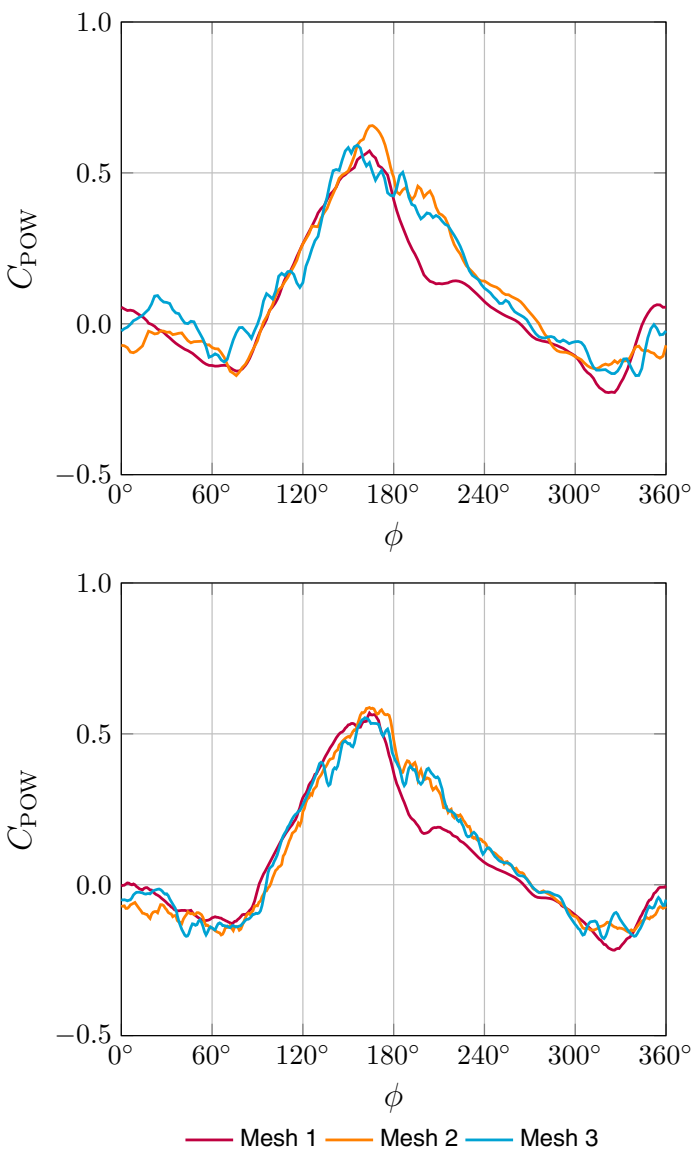

Fig. $52 \mathrm{D}$ case. $C_{\mathrm{POW}}$, for $\Delta \phi=2^{\circ}$ (top) and $1^{\circ}$ (bottom), averaged over the three blades in the last three rotations

\subsection{D case}

We first compute with TSR $=2$. The model geometry and the SI are shown in Fig. 3. The boundary conditions are $U_{\infty}$ at the inflow, zero stress at the outflow, slip at the lateral boundaries, and no-slip on the rotor and support column surfaces. The prescribed velocities are evaluated at the time integration points, with the values extracted from the NURBS representation of the prescribed motion.

We use three different meshes. We start with Mesh 1, and obtain the other two meshes by knot insertion. We halve the knot spacing to get Mesh 2, and halve it again to get Mesh 3. Figure 4 shows Mesh 3. The number of control points and elements are shown in Table 1 . We compute for 10 rotations. Figure 5 shows, for $\Delta \phi=2^{\circ}$ and $1^{\circ}, C_{\text {POW }}$, averaged over the three blades in the last three rotations. The results from 


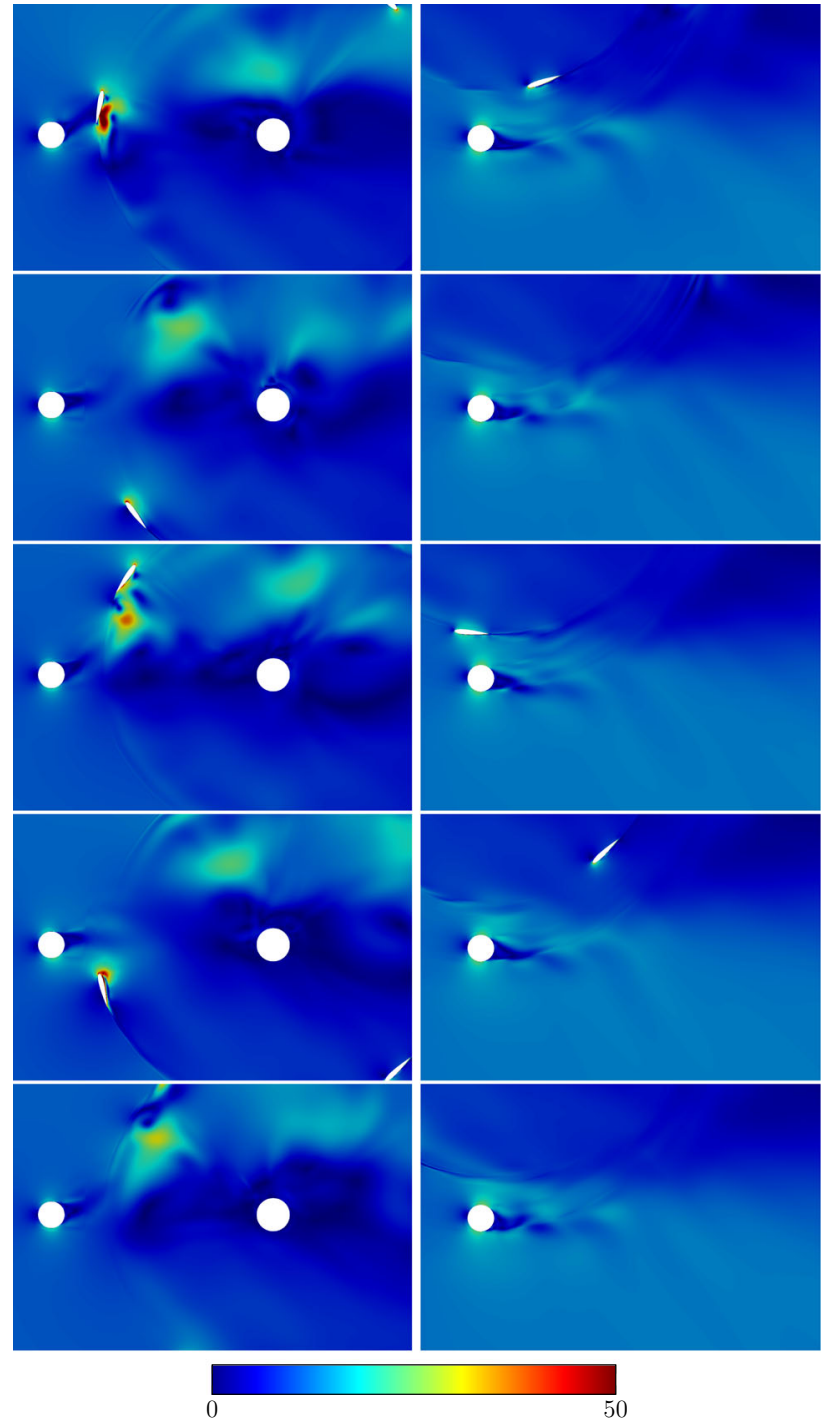

Fig. 6 2D case. Velocity magnitude (m/s) for Mesh 1 with $\Delta \phi=1^{\circ}$ in the wake of the support columns located at $\phi=180^{\circ}$ (left) and $90^{\circ}$ (right), in the last rotation, for $t / T$ ranging from 0.2 to 1

different combinations of spatial and temporal resolutions are mostly in agreement. The cases with the lower spatial resolution and highest Courant number show some differences in parts of the rotation cycle. Figures 6 and 7 show, for Mesh 1 with $\Delta \phi=1^{\circ}$ and Mesh 2 with $\Delta \phi=2^{\circ}$, the velocity magnitude in the wake of the support columns located at $\phi=180^{\circ}$ and $\phi=90^{\circ}$. Mesh 1 , with even $\Delta \phi=1^{\circ}$, is not able to capture the wake as well as Mesh 2 does even with $\Delta \phi=2^{\circ}$. This indicates that a reasonable level of mesh refinement is needed. Table 2 shows $C_{\mathrm{POW}}$ averaged over the three blades in the last three rotations and the standard deviation $\left(\sigma_{\mathrm{CPOW}}\right)$ associated with that, both averaged over the rotation cycle. We believe the higher $\sigma_{\mathrm{CPOW}}$ values we see at higher Courant numbers are caused by strong vortices, which we do not believe to be representative of what actually happens in 3D.

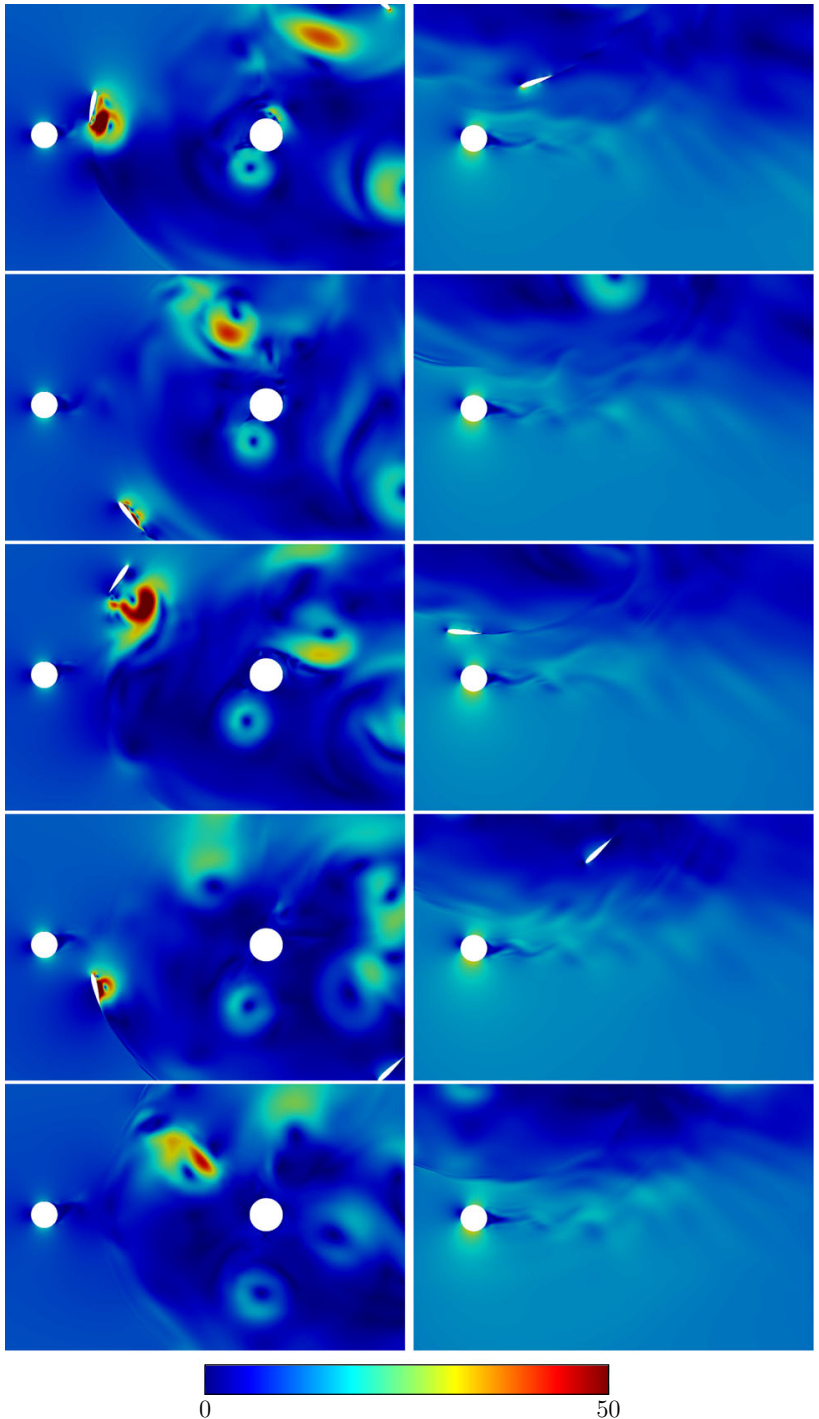

Fig. $72 \mathrm{D}$ case. Velocity magnitude $(\mathrm{m} / \mathrm{s})$ for Mesh 2 with $\Delta \phi=2^{\circ}$ in the wake of the support columns located at $\phi=180^{\circ}$ (left) and $90^{\circ}$ (right), in the last rotation, for $t / T$ ranging from 0.2 to 1

Table 2 2D case. $C_{\text {POW }}$ averaged over the three blades in the last three rotations and the standard deviation associated with that, both averaged over the rotation cycle

\begin{tabular}{llll}
\hline Mesh & $\Delta \phi$ & $C_{\text {POW }}$ & $\sigma_{\text {CPOW }}$ \\
\hline Mesh 1 & $2^{\circ}$ & 0.0760 & 0.0447 \\
Mesh 1 & $1^{\circ}$ & 0.0766 & 0.0439 \\
Mesh 2 & $2^{\circ}$ & 0.1107 & 0.0955 \\
Mesh 2 & $1^{\circ}$ & 0.0867 & 0.0751 \\
Mesh 3 & $2^{\circ}$ & 0.1183 & 0.0773 \\
Mesh 3 & $1^{\circ}$ & 0.0883 & 0.0692 \\
\hline
\end{tabular}




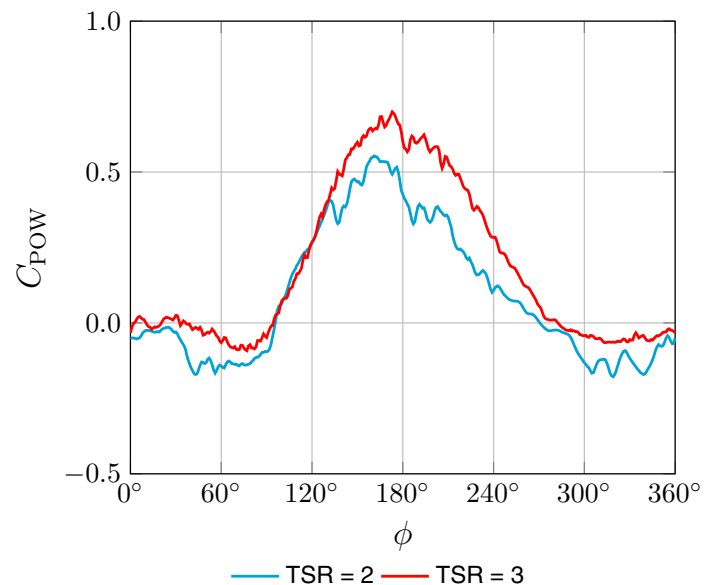

Fig. 8 2D case. $C_{\text {POW }}$ for TSR $=2$ and 3, computed with Mesh 3 and $\Delta \phi=1^{\circ}$, averaged over the three blades in the last three rotations
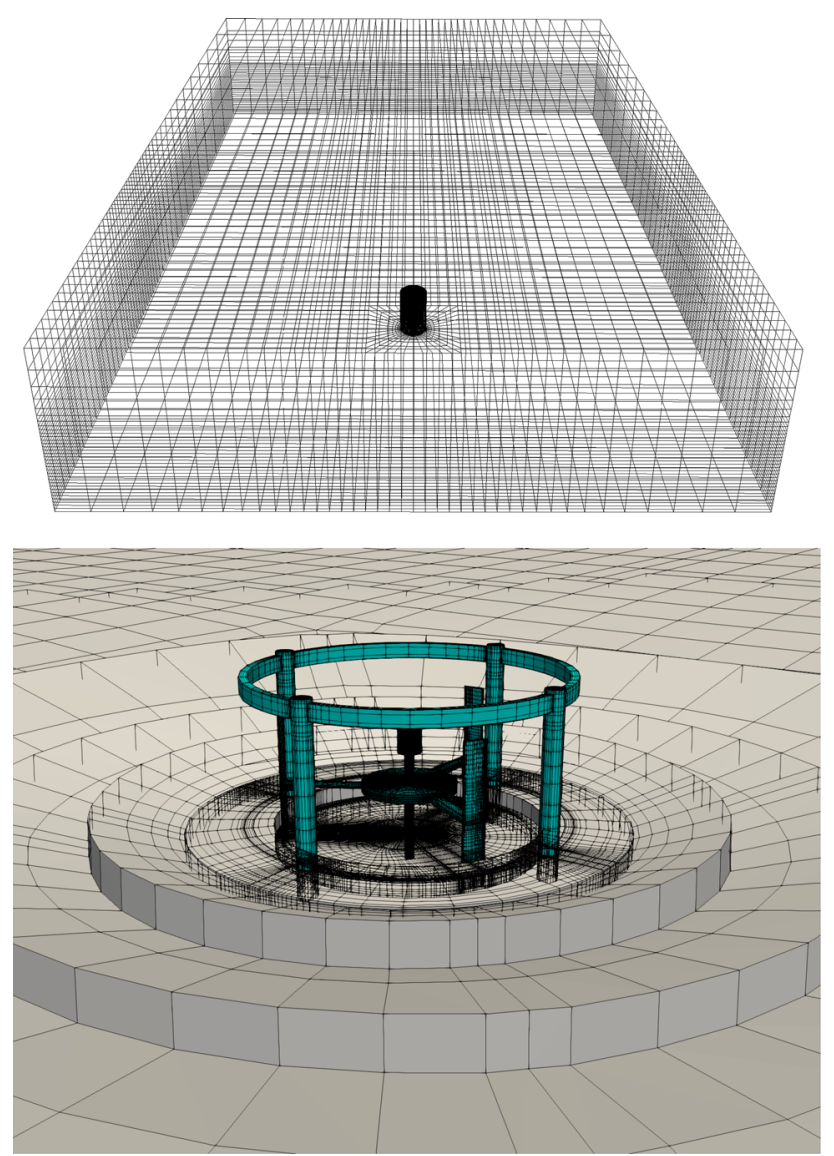

Fig. 9 3D case. Initial mesh (control mesh)

We also compute with TSR $=3$. We use Mesh 3 with $\Delta \phi=1^{\circ}$. Figure 8 shows $C_{\text {POW }}$, averaged over the three blades in the last three rotations, for TSR $=3$ and 2. Rotationcycle-averaged value of $C_{\mathrm{POW}}$ is 0.18 , which is significantly larger than what we have for TSR $=2$, translates to a total

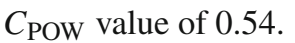
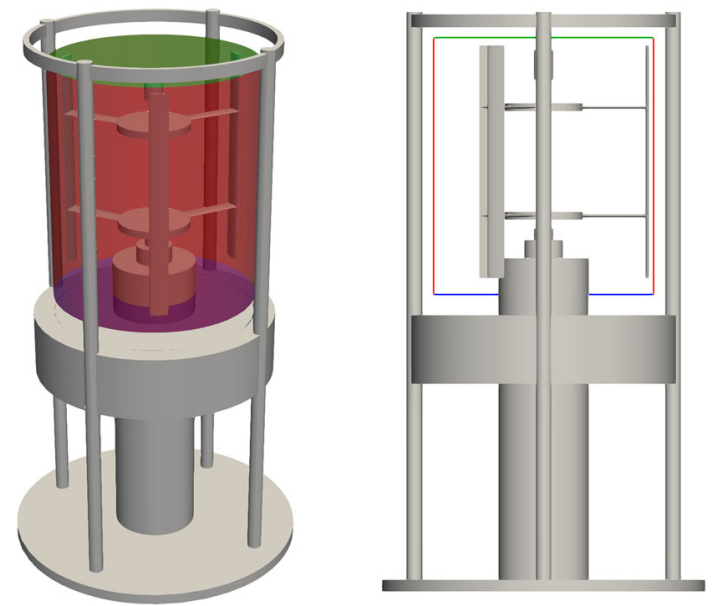

Fig. 10 3D case. The three SIs, marked in color, with an actual slip. 3D view (left) and vertical cut plane (right)
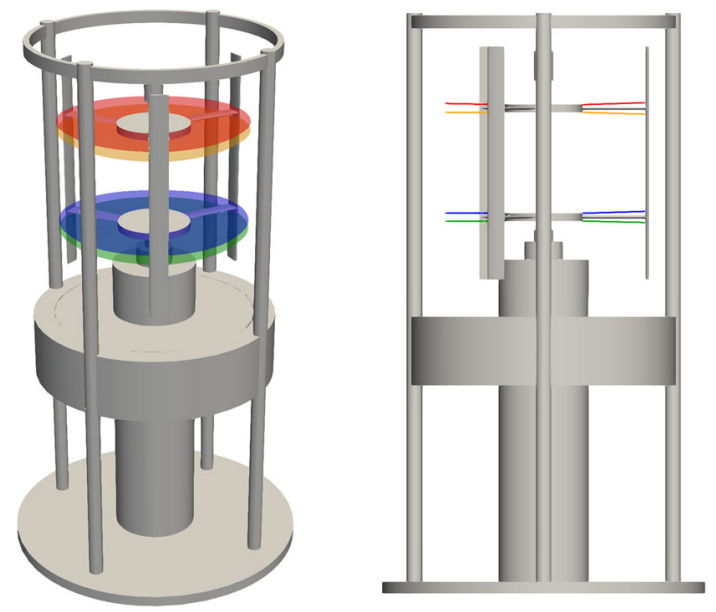

Fig. 11 3D case. The four SIs, marked in color, that are for mesh generation purposes and in the rotating mesh. 3D view (left) and vertical cut plane (right)

\subsection{D case}

We compute with TSR $=3$. The boundary conditions are noslip on all turbine surfaces and the bottom boundary, $U_{\infty}$ at the inflow, zero stress at the outflow, and slip at the lateral and top boundaries. All prescribed velocities are evaluated at the time integration points with the values extracted from the NURBS representation of the prescribed motion.

Figure 9 shows the initial mesh, generated with the method in [26]. There are 1,544,460 control points and 955,477 quadratic NURBS elements. There are total nine SIs in the mesh. Figure 10 shows the SIs with an actual slip. Figures 11 and 12 show the SIs that are just for mesh generation purposes.

To improve the mesh quality, we use the mesh relaxation method introduced in [28], which is based on fiber-reinforced hyperelasticity and optimized ZSS. The hyperelasticity 


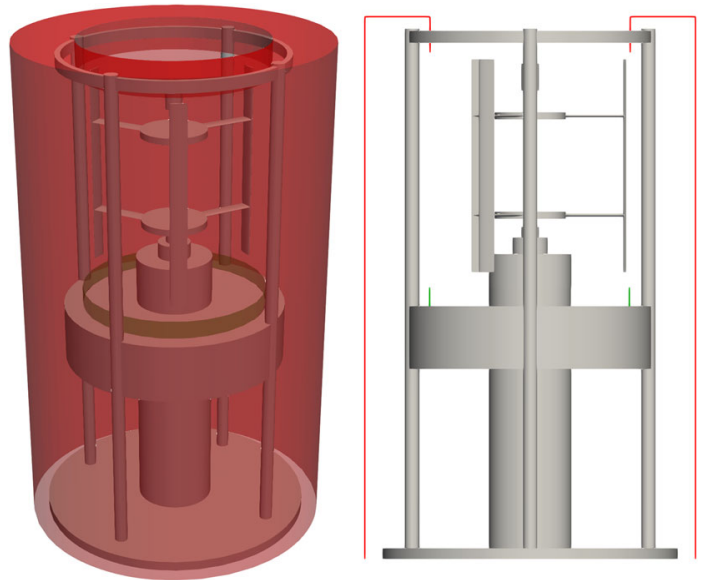

Fig. 12 3D case. The two SIs, marked in color, that are for mesh generation purposes and in the stationary mesh. 3D view (left) and vertical cut plane (right)
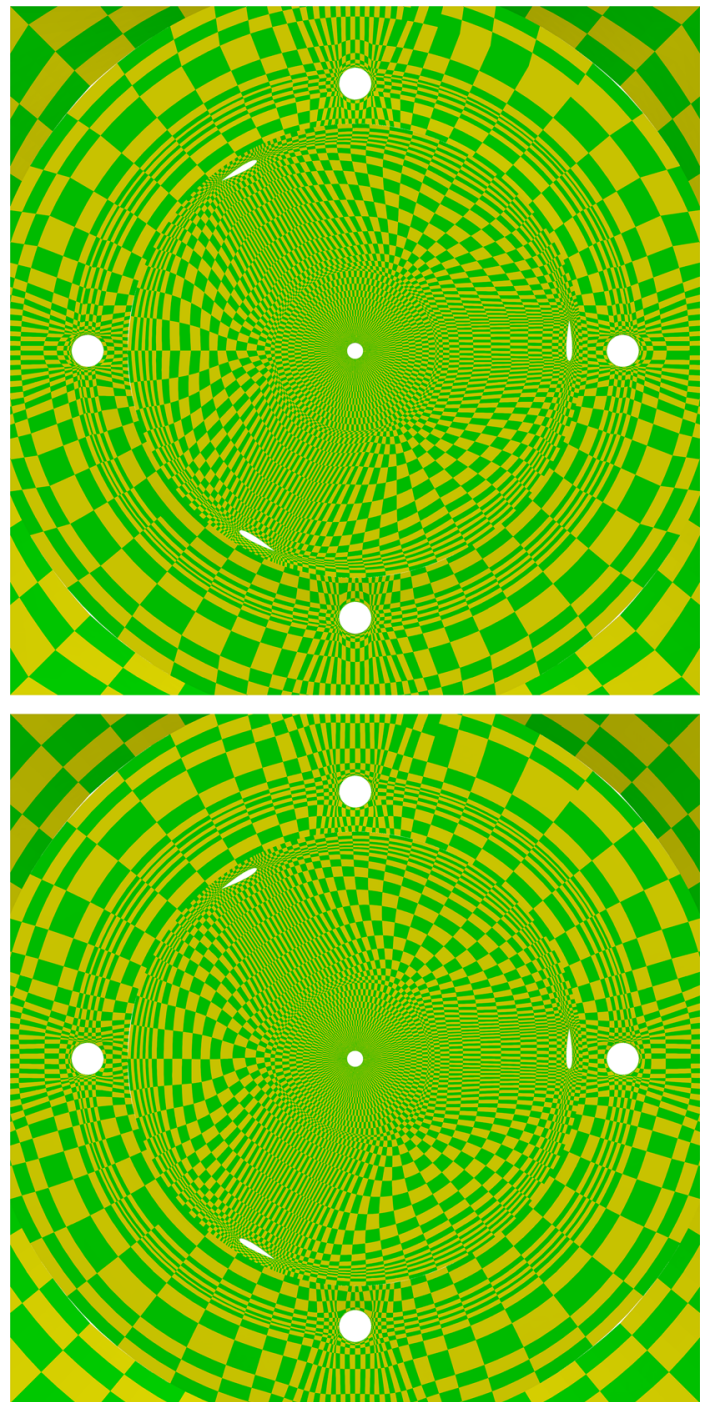

Fig. 13 3D case. Horizontal cut plane. Initial mesh (top) and mesh after the relaxation (bottom)

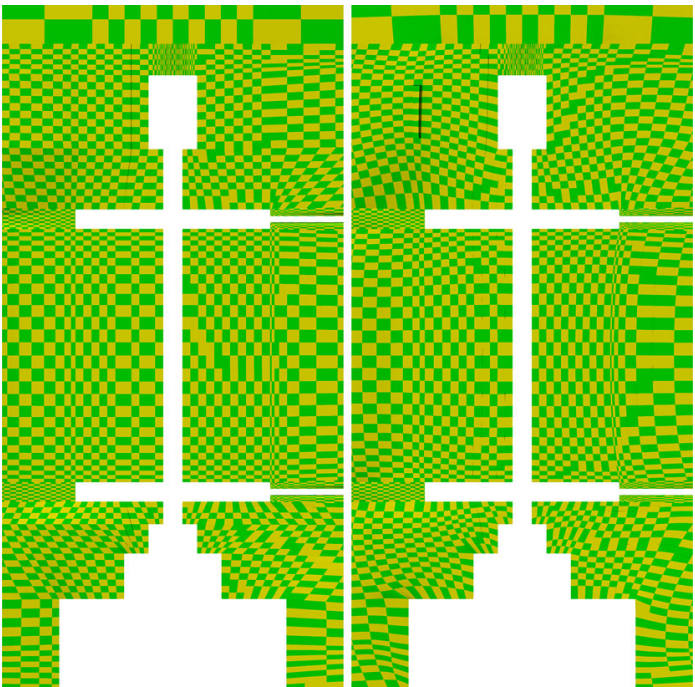

Fig. 14 3D case. Vertical cut plane. Initial mesh (left) and mesh after the relaxation $(r i g h t)$

model is the one given by Eqs. (48), (39), (50) and (51) in [28], with $\kappa=0$. The material properties are $\kappa_{\mathrm{B}}=10^{-2}$, $\beta_{\mathrm{B}}=2, \mu=1, C_{1}=100$, and $C_{2}=10^{-2}$. We ramp-up to the optimized ZSS in 10 equal increments. For the numerical integration, $4 \times 4 \times 4$ quadrature points are used. Figures 13 and 14 show the initial mesh and the mesh after the relaxation. We clearly see the improvement in the mesh-line orthogonality, without much change in the element aspect ratio or the local resolution.

We compute for two rotations and report the solution from the last rotation. Figure 15 shows the isosurfaces of the second invariant of the velocity gradient tensor near a blade, at different positions of the blade. Figure 16 shows $C_{\text {POW }}$. The total $C_{\text {POW }}$ averaged over the rotation cycle is about 0.56 . Figure 17 shows $C_{\mathrm{POW}}$ from the $2 \mathrm{D}$ and $3 \mathrm{D}$ computations, averaged over the three blades. They are in reasonably good agreement, considering that the space dimensions are not the same. The 3D value is slightly higher in an average sense. Because the shelter and the upper part of the frame divert some of the flow to the rotor, the blades see more flow than what corresponds to the projected area calculated using the blade height.

\section{Concluding remarks}

We have presented computational flow analysis of a VAWT that has been proposed to also serve as a tsunami shelter. The turbine has, in addition to the three-blade rotor, four support columns at the periphery, which support the turbine rotor and the shelter. The computational challenges encountered in flow analysis of the tsunami-shelter VAWT include those encountered in flow analysis of wind turbines in gen- 


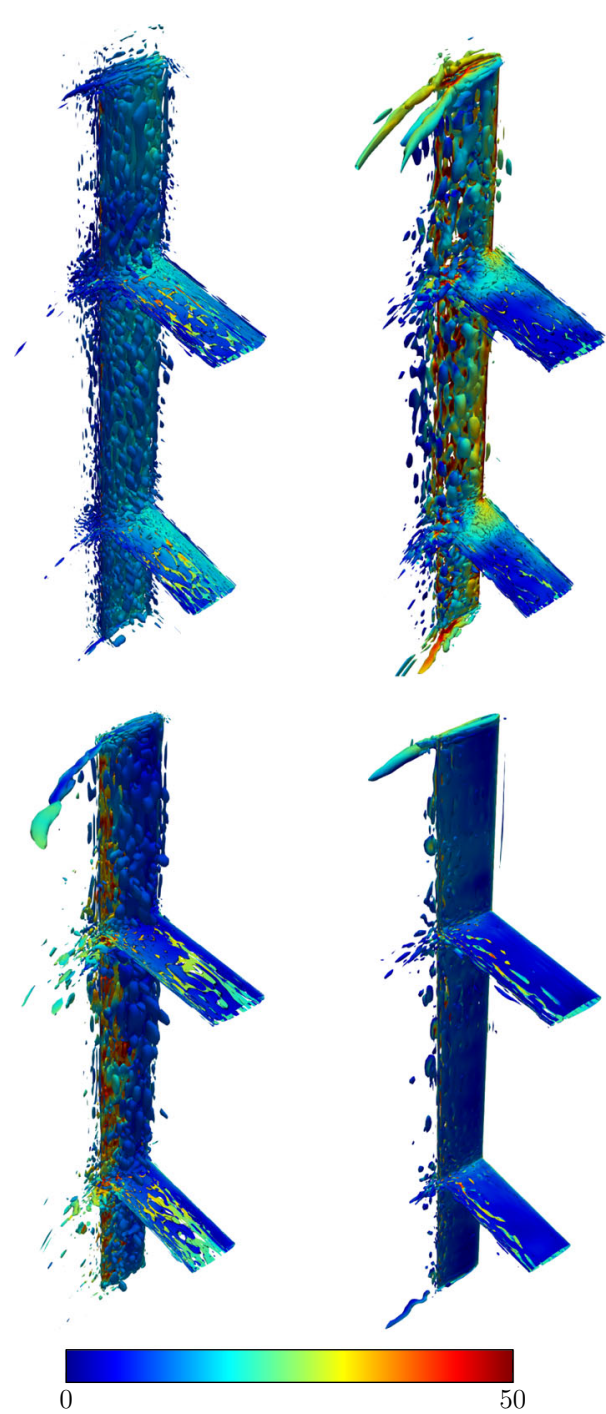

Fig. $153 \mathrm{D}$ case. Isosurfaces corresponding to a positive value of the second invariant of the velocity gradient tensor, colored by the velocity magnitude $\left(\mathrm{m} / \mathrm{s}\right.$ ), at $\phi=90^{\circ}, 180^{\circ}, 270^{\circ}$ and $360^{\circ}$ (from left to right and top to bottom) in the last rotation

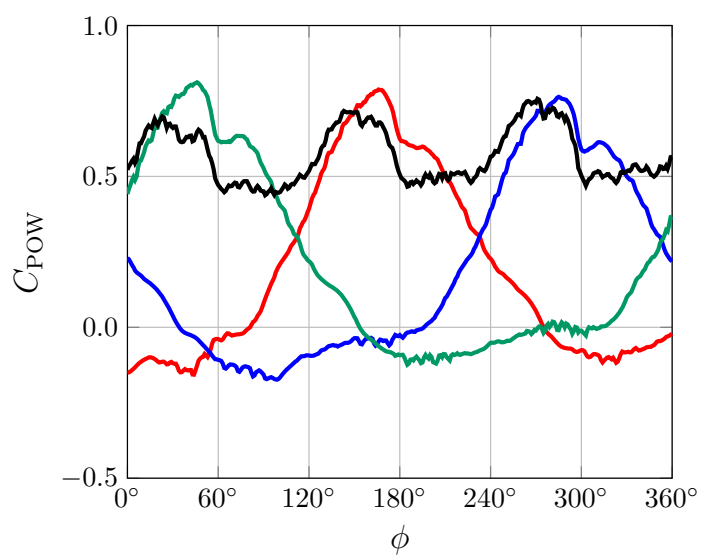

Fig. $163 \mathrm{D}$ case. $C_{\mathrm{POW}}$ for the three blades (red, blue, green) and the total $C_{\mathrm{POW}}$, in the last rotation, at instants defined by the position of the red blade

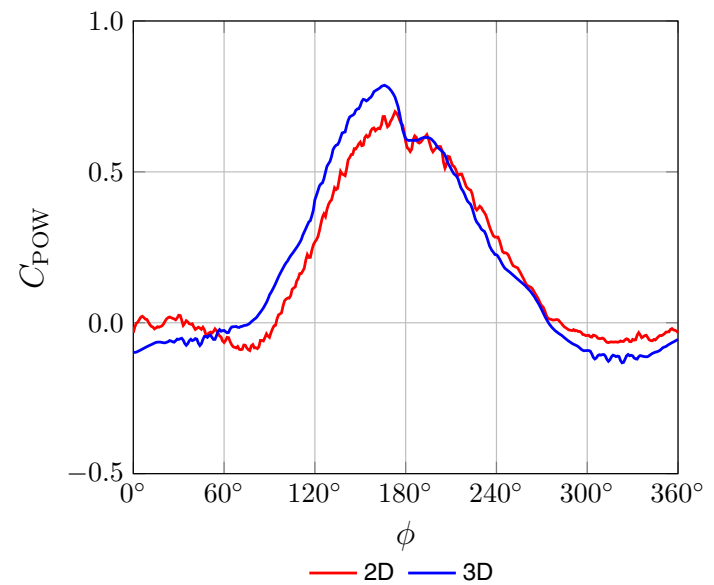

Fig. $17 C_{\text {POW }}$ from the $2 \mathrm{D}$ and $3 \mathrm{D}$ computations, averaged over the three blades, in the last three rotations for the $2 \mathrm{D}$ case and in the last rotation for the $3 \mathrm{D}$ case

eral, such as accurate representation of the turbine geometry, multiscale unsteady flow, and moving-boundary flow associated with the rotor motion. Beyond those, because of its rather high geometric complexity, the tsunami-shelter VAWT poses the challenge of reaching high accuracy in turbine-geometry representation and flow solution when the geometry is so complex.

We address the challenges with an ST computational method that integrates three special ST methods around a core ST method and mesh-related methods. The core method is the ST-VMS, which subsumes its precursor ST-SUPS. The three special methods are the ST-SI, ST-IGA, and the STNMUM. The mesh-related methods are a general-purpose NURBS mesh generation method and a mesh relaxation method based on fiber-reinforced hyperelasticity and optimized ZSS.

The ST-discretization feature of the integrated method provides higher-order accuracy compared to standard discretization methods. The VMS feature addresses the computational challenges associated with the multiscale nature of the unsteady flow. The moving-mesh feature of the ST framework enables high-resolution computation near the blades. The ST-SI enables moving-mesh computation of the spinning rotor. The mesh covering the rotor spins with it, and the SI between the spinning mesh and the rest of the mesh accurately connects the two sides of the solution. The STIGA enables more accurate representation of the blade and other turbine geometries and increased accuracy in the flow solution. The STNMUM enables exact representation of the mesh rotation. The general-purpose NURBS mesh generation method makes it easier to deal with the complex turbine geometry. The quality of the mesh generated with this method is improved with the mesh relaxation method. 
We have presented computations for the 2D and 3D cases. In the 2D case, we have presented computations for three different meshes, two different time-step sizes, and two different tip-speed ratios. In the 3D case, we computed with one of the combinations of the 2D case and compared the 2D and 3D results. The computations show the effectiveness of our ST and mesh generation and relaxation methods in flow analysis of the tsunami-shelter VAWT.

Acknowledgements This work was supported in part by Grant-in-Aid for Challenging Exploratory Research 16K13779 from Japan Society for the Promotion of Science; Grant-in-Aid for Scientific Research (S) 26220002 from the Ministry of Education, Culture, Sports, Science and Technology of Japan (MEXT); Council for Science, Technology and Innovation (CSTI), Cross-Ministerial Strategic Innovation Promotion Program (SIP), "Innovative Combustion Technology" (Funding agency: JST); and Rice-Waseda research agreement. This work was also supported (fourth author) in part by ARO Grant W911NF-17-10046 and Top Global University Project of Waseda University. The authors acknowledge the Texas Advanced Computing Center (TACC) at The University of Texas at Austin for providing HPC resources that have contributed to the research results reported within this paper.

Open Access This article is licensed under a Creative Commons Attribution 4.0 International License, which permits use, sharing, adaptation, distribution and reproduction in any medium or format, as long as you give appropriate credit to the original author(s) and the source, provide a link to the Creative Commons licence, and indicate if changes were made. The images or other third party material in this article are included in the article's Creative Commons licence, unless indicated otherwise in a credit line to the material. If material is not included in the article's Creative Commons licence and your intended use is not permitted by statutory regulation or exceeds the permitted use, you will need to obtain permission directly from the copyright holder. To view a copy of this licence, visit http://creativecomm ons.org/licenses/by/4.0/.

\section{A Stabilization parameters}

\section{A.1 ST-VMS}

There are various ways of defining the stabilization parameters $\tau_{\text {SUPS }}$ and $\nu_{\text {LSIC. Here, }} \tau_{\text {SUPS }}$ is mostly from [142]:

$\tau_{\mathrm{SUPS}}=\left(\tau_{\mathrm{SUGN} 12}^{-2}+\tau_{\mathrm{SUGN} 3}^{-2}+\tau_{\mathrm{SUGN} 4}^{-2}\right)^{-\frac{1}{2}}$.

The first and second components are given as

$\tau_{\mathrm{SUGN} 12}^{-2}=\left[\begin{array}{l}1 \\ \mathbf{u}\end{array}\right]\left[\begin{array}{l}1 \\ \mathbf{u}\end{array}\right]: \mathbf{G}^{\mathrm{ST}}$

and

$\tau_{\mathrm{SUGN} 3}^{-1}=v \mathbf{r r}: \mathbf{G}$, where $\mathbf{r}$ is the solution-gradient direction:

$\mathbf{r}=\frac{\nabla\|\mathbf{u}\|}{\|\nabla\| \mathbf{u}\|\|}$.

Here $\mathbf{G}^{\mathbf{S T}}$ and $\mathbf{G}$ are the ST and space-only element metric tensors:

$$
\begin{aligned}
\mathbf{G}^{\mathrm{ST}} & =\left(\hat{\mathbf{Q}}^{\mathrm{ST}}\right)^{-T} \cdot\left(\hat{\mathbf{Q}}^{\mathrm{ST}}\right)^{-1}, \\
\mathbf{G} & =\hat{\mathbf{Q}}^{-T} \cdot \hat{\mathbf{Q}}^{-1},
\end{aligned}
$$

where

$$
\begin{aligned}
\hat{\mathbf{Q}}^{\mathrm{ST}} & =\mathbf{Q}^{\mathrm{ST}} \cdot\left(\mathbf{D}^{\mathrm{ST}}\right)^{-1}, \\
\hat{\mathbf{Q}} & =\mathbf{Q} \cdot \mathbf{D}^{-1} .
\end{aligned}
$$

The ST and space-only Jacobian tensors are

$\mathbf{Q}^{\mathrm{ST}}=\left[\begin{array}{ll}\frac{\partial t}{\partial \theta} & \frac{\partial t}{\partial \boldsymbol{\xi}} \\ \frac{\partial \mathbf{x}}{\partial \theta} & \mathbf{Q}\end{array}\right]$

and

$\mathbf{Q}=\frac{\partial \mathbf{x}}{\partial \boldsymbol{\xi}}$,

where $\theta$ and $\boldsymbol{\xi}$ are the temporal and spatial parametric coordinates. The transformation tensor $\mathbf{D}^{\mathrm{ST}}$ is defined as

$\mathbf{D}^{\mathrm{ST}}=\left[\begin{array}{cc}D_{\theta} & \mathbf{0}^{T} \\ \mathbf{0} & \mathbf{D}\end{array}\right]$.

The definitions used for $D_{\theta}$ and $\mathbf{D}$ play an important role, especially for higher-order isogeometric discretization [142, 144] and simplex elements [143].

In this article, we set $D_{\theta}=1$ and set D to its "RQD-MAX" version [144].

The third component, originating from [18], is defined as

$\tau_{\mathrm{SUGN} 4}=\left\|\boldsymbol{\nabla} \mathbf{u}^{h}\right\|_{F}^{-1}$,

where $\|\cdot\|_{F}$ represents the Frobenius norm.

The stabilization parameter $v_{\text {LSIC }}$ is from [25]:

$\nu_{\mathrm{LSIC}}=\frac{h_{\mathrm{LSIC}}^{2}}{\tau_{\mathrm{SUPS}}}$,

where $h_{\text {LSIC }}$ is set equal to the minimum element length $h_{\text {MIN }}$ :

$h_{\mathrm{MIN}}=2\left(\max _{\mathbf{r}}(\mathbf{r r}: \mathbf{G})\right)^{-\frac{1}{2}}$. 
For more ways of calculating the stabilization parameters in flow computations, see [2,3,5,7-9,141,146-152].

\section{A.2 ST-SI}

The element length used in the ST-SI is given as

$$
\begin{aligned}
h & =\left(\frac{h_{\mathrm{B}}^{-2}+h_{\mathrm{A}}^{-2}}{2}\right)^{-\frac{1}{2}}, \\
h_{\mathrm{B}} & =2\left(\mathbf{n}_{\mathrm{B}} \mathbf{n}_{\mathrm{B}}: \mathbf{G}\right)^{-\frac{1}{2}} \\
h_{\mathrm{A}} & =2\left(\mathbf{n}_{\mathrm{A}} \mathbf{n}_{\mathrm{A}}: \mathbf{G}\right)^{-\frac{1}{2}} \\
\hat{\mathbf{n}}_{\mathrm{B}} & =\frac{\mathbf{n}_{\mathrm{B}}-\mathbf{n}_{\mathrm{A}}}{\left\|\mathbf{n}_{\mathrm{B}}-\mathbf{n}_{\mathrm{A}}\right\|} .
\end{aligned}
$$$$
\text { (for Side B), }
$$$$
\text { (for Side A), }
$$

Remark 2 We note that the expression for $h$ given by Eq. (24) is slightly different from its original form introduced in [131]:

$$
h=\left(\frac{h_{\mathrm{B}}^{-1}+h_{\mathrm{A}}^{-1}}{2}\right)^{-1} \text {. }
$$

The modification, which has only minor effect, is for consistency with how the stabilization parameters are calculated from their components and for implementation convenience.

\section{References}

1. Life tower: wind power tower with tsunami evacuation shelter. http://cosmosunfarm.co.jp/lifetower.html

2. Corsini A, Rispoli F, Sheard AG, Tezduyar TE (2012) Computational analysis of noise reduction devices in axial fans with stabilized finite element formulations. Comput Mech 50:695-705. https://doi.org/10.1007/s00466-012-0789-4

3. Corsini A, Rispoli F, Sheard AG, Takizawa K, Tezduyar TE, Venturini P (2014) A variational multiscale method for particle-cloud tracking in turbomachinery flows. Comput Mech 54:1191-1202. https://doi.org/10.1007/s00466-014-1050-0

4. Cardillo L, Corsini A, Delibra G, Rispoli F, Tezduyar TE (2016) Flow analysis of a wave-energy air turbine with the SUPG/PSPG method and DCDD. In: Bazilevs Y, Takizawa K (eds) Advances in computational fluid-structure interaction and flow simulation: new methods and challenging computations, modeling and simulation in science, engineering and technology, pp. 3953, Springer, ISBN 978-3-319-40825-5, https://doi.org/10.1007/ 978-3-319-40827-9_4

5. Cardillo L, Corsini A, Delibra G, Rispoli F, Tezduyar TE (2016) Flow analysis of a wave-energy air turbine with the SUPG/PSPG stabilization and Discontinuity-Capturing Directional Dissipation. Comput Fluids 141:184-190. https://doi.org/ 10.1016/j.compfluid.2016.07.011

6. Castorrini A, Corsini A, Rispoli F, Venturini P, Takizawa K, Tezduyar TE (2016) SUPG/PSPG computational analysis of rain erosion in wind-turbine blades. In: Bazilevs Y, Takizawa K (eds) Advances in computational fluid-structure interaction and flow simulation: new methods and challenging computations, modeling and simulation in science, engineering and technology, pp.
77-96, Springer, ISBN 978-3-319-40825-5, https://doi.org/10. 1007/978-3-319-40827-9_7

7. Castorrini A, Corsini A, Rispoli F, Venturini P, Takizawa K, Tezduyar TE (2016) Computational analysis of wind-turbine blade rain erosion. Comput Fluids 141:175-183. https://doi.org/10. 1016/j.compfluid.2016.08.013

8. Castorrini A, Corsini A, Rispoli F, Takizawa K, Tezduyar TE (2019) A stabilized ALE method for computational fluid-structure interaction analysis of passive morphing in turbomachinery. Math Models Methods Appl Sci 29:967-994. https://doi.org/10.1142/ S0218202519410057

9. Castorrini A, Corsini A, Rispoli F, Venturini P, Takizawa K, Tezduyar TE (2019) Computational analysis of performance deterioration of a wind turbine blade strip subjected to environmental erosion. Comput Mech 64:1133-1153. https://doi.org/10.1007/ s00466-019-01697-0

10. Bazilevs Y, Hsu M-C, Akkerman I, Wright S, Takizawa K, Henicke B, Spielman T, Tezduyar TE (2011) 3D simulation of wind turbine rotors at full scale. Part I: geometry modeling and aerodynamics. Int J Numer Meth Fluids 65:207-235. https://doi. org/10.1002/fld.2400

11. Bazilevs Y, Takizawa K, Tezduyar TE, Hsu M-C, Kostov N, McIntyre S (2014) Aerodynamic and FSI analysis of wind turbines with the ALE-VMS and ST-VMS methods. Arch Comput Methods Eng 21:359-398. https://doi.org/10.1007/s11831-014-9119-7

12. Korobenko A, Bazilevs Y, Takizawa K, Tezduyar TE (2018) Recent advances in ALE-VMS and ST-VMS computational aerodynamic and FSI analysis of wind turbines. In: Tezduyar TE (eds) Frontiers in computational fluid-structure interaction and flow simulation: research from lead investigators under forty -2018 , Modeling and simulation in science, engineering and technology, pp. 253-336, Springer, ISBN 978-3-319-96468-3, https://doi.org/ 10.1007/978-3-319-96469-0_7

13. Korobenko A, Bazilevs Y, Takizawa K, Tezduyar TE (2019) Computer modeling of wind turbines: 1. ALE-VMS and STVMS aerodynamic and FSI analysis. Arch Comput Methods Eng 26:1059-1099. https://doi.org/10.1007/s11831-018-9292-1

14. Bazilevs Y, Takizawa K, Tezduyar TE, Hsu M-C, Otoguro Y, Mochizuki H, Wu MCH (2020) Wind turbine and turbomachinery computational analysis with the ALE and space-time variational multiscale methods and isogeometric discretization. J Adv Eng Comput 4:1-32. https://doi.org/10.25073/jaec.202041.278

15. Bazilevs Y, Takizawa K, Tezduyar TE, Hsu M-C, Otoguro Y, Mochizuki H, Wu MCH (2020) ALE and space-time variational multiscale isogeometric analysis of wind turbines and turbomachinery. In Grama A, Sameh A (eds) Parallel algorithms in computational science and engineering, Modeling and simulation in science, engineering and technology, pp. 195-233, Springer, ISBN 978-3-030-43735-0, https://doi.org/10.1007/978-3-03043736-7_7

16. Takizawa K, Tezduyar TE (2011) Multiscale space-time fluidstructure interaction techniques. Comput Mech 48:247-267. https://doi.org/10.1007/s00466-011-0571-z

17. Takizawa K, Tezduyar TE (2012) Space-time fluidstructure interaction methods. Math Models Methods Appl Sci 22(supp02):1230001. https://doi.org/10.1142/ S0218202512300013

18. Takizawa K, Tezduyar TE, Kuraishi T (2015) Multiscale ST methods for thermo-fluid analysis of a ground vehicle and its tires. Math Models Methods Appl 1 Sci 25:2227-2255. https://doi.org/ 10.1142/S0218202515400072

19. Takizawa K, Tezduyar TE, Mochizuki H, Hattori H, Mei S, Pan L, Montel K (2015) Space-time VMS method for flow computations with slip interfaces (ST-SI). Math Models Methods Appl Sci 25:2377-2406. https://doi.org/10.1142/S0218202515400126 
20. Takizawa K, Tezduyar TE, Kuraishi T, Tabata S, Takagi H (2016) Computational thermo-fluid analysis of a disk brake. Comput Mech 57:965-977. https://doi.org/10.1007/s00466-016-1272-4

21. Takizawa K, Henicke B, Puntel A, Spielman T, Tezduyar TE (2012) Space-time computational techniques for the aerodynamics of flapping wings. J Appl Mech 79:010903. https://doi.org/10. $1115 / 1.4005073$

22. Takizawa K, Tezduyar TE, Otoguro Y, Terahara T, Kuraishi T, Hattori H (2017) Turbocharger flow computations with the spacetime isogeometric analysis (ST-IGA). Comput Fluids 142:15-20. https://doi.org/10.1016/j.compfluid.2016.02.021

23. Takizawa K, Henicke B, Puntel A, Kostov N, Tezduyar TE (2012) Space-time techniques for computational aerodynamics modeling of flapping wings of an actual locust. Comput Mech 50:743-760. https://doi.org/10.1007/s00466-012-0759-x

24. Takizawa K, Kostov N, Puntel A, Henicke B, Tezduyar TE (2012) Space-time computational analysis of bio-inspired flapping-wing aerodynamics of a micro aerial vehicle. Comput Mech 50:761778. https://doi.org/10.1007/s00466-012-0758-y

25. Takizawa K, Tezduyar TE, McIntyre S, Kostov N, Kolesar R, Habluetzel C (2014) Space-time VMS computation of windturbine rotor and tower aerodynamics. Comput Mech 53:1-15. https://doi.org/10.1007/s00466-013-0888-x

26. Otoguro Y, Takizawa K, Tezduyar TE (2017) Space-time VMS computational flow analysis with isogeometric discretization and a general-purpose NURBS mesh generation method. Computers \& Fluids 158:189-200. https://doi.org/10.1016/j.compfluid. 2017.04.017

27. Otoguro Y, Takizawa K, Tezduyar TE (2018) A general-purpose NURBS mesh generation method for complex geometries. In: Tezduyar TE (eds) Frontiers in computational fluid-structure interaction and flow simulation: research from lead investigators under forty -2018 , Modeling and simulation in science, engineering and technology, pp. 399-434, Springer, ISBN 978-3319-96468-3, https://doi.org/10.1007/978-3-319-96469-0_10

28. Takizawa K, Tezduyar TE, Avsar R (2020) A low-distortion mesh moving method based on fiber-reinforced hyperelasticity and optimized zero-stress state. Comput Mech 65:1567-1591. https://doi. org/10.1007/s00466-020-01835-z

29. Takizawa K, Bazilevs Y, Tezduyar TE, Korobenko A (2020) Variational multiscale flow analysis in aerospace, energy and transportation technologies. J Adv Eng Comput 4:83-117. https:// doi.org/10.25073/jaec.202042.279

30. Takizawa K, Bazilevs Y, Tezduyar TE, Korobenko A (2020) Variational multiscale flow analysis in aerospace, energy and transportation technologies. In: Grama A, Sameh A (eds) Parallel algorithms in computational science and engineering, modeling and simulation in science, engineering and technology, pp. 235-280, Springer, ISBN 978-3-030-43735-0, https://doi.org/10. 1007/978-3-030-43736-7_8

31. Tezduyar TE (1992) Stabilized finite element formulations for incompressible flow computations. Adv Appl Mech 28:1-44. https://doi.org/10.1016/S0065-2156(08)70153-4

32. Tezduyar TE (2003) Computation of moving boundaries and interfaces and stabilization parameters. Int J Numer Meth Fluids 43:555-575. https://doi.org/10.1002/fld.505

33. Tezduyar TE, Sathe S (2007) Modeling of fluid-structure interactions with the space-time finite elements: Solution techniques. Int J Numer Meth Fluids 54:855-900. https://doi.org/10.1002/fld. 1430

34. Brooks AN, Hughes TJR (1982) Streamline upwind/PetrovGalerkin formulations for convection dominated flows with particular emphasis on the incompressible Navier-Stokes equations. Comput Methods Appl Mech Eng 32:199-259

35. Hughes TJR (1995) Multiscale phenomena: Green's functions, the Dirichlet-to-Neumann formulation, subgrid scale models, bub- bles, and the origins of stabilized methods. Comput Methods Appl Mech Eng 127:387-401

36. Hughes TJR, Oberai AA, Mazzei L (2001) Large eddy simulation of turbulent channel flows by the variational multiscale method. Phys Fluids 13:1784-1799

37. Bazilevs Y, Calo VM, Cottrell JA, Hughes TJR, Reali A, Scovazzi G (2007) Variational multiscale residual-based turbulence modeling for large eddy simulation of incompressible flows. Comput Methods Appl Mech Eng 197:173-201

38. Bazilevs Y, Akkerman I (2010) Large eddy simulation of turbulent Taylor-Couette flow using isogeometric analysis and the residualbased variational multiscale method. J Comput Phys 229:34023414

39. Hughes TJR, Liu WK, Zimmermann TK (1981) LagrangianEulerian finite element formulation for incompressible viscous flows. Comput Methods Appl Mech Eng 29:329-349

40. Bazilevs Y, Calo VM, Hughes TJR, Zhang Y (2008) Isogeometric fluid-structure interaction: theory, algorithms, and computations. Comput Mech 43:3-37

41. Takizawa K, Bazilevs Y, Tezduyar TE (2012) Space-time and ALE-VMS techniques for patient-specific cardiovascular fluidstructure interaction modeling. Arch Comput Methods Eng 19:171-225. https://doi.org/10.1007/s11831-012-9071-3

42. Bazilevs Y, Hsu M-C, Takizawa K, Tezduyar TE (2012) ALEVMS and ST-VMS methods for computer modeling of windturbine rotor aerodynamics and fluid-structure interaction. Math Models Methods Appl Sci 22(supp02):1230002. https://doi.org/ 10.1142/S0218202512300025

43. Bazilevs Y, Takizawa K, Tezduyar TE (2013) computational fluidstructure interaction: methods and applications. Wiley, Hoboken, ISBN 978-0470978771

44. Bazilevs Y, Takizawa K, Tezduyar TE (2013) Challenges and directions in computational fluid-structure interaction. Math Models Methods Appl Sci 23:215-221. https://doi.org/10.1142/ S0218202513400010

45. Bazilevs Y, Takizawa K, Tezduyar TE (2015) New directions and challenging computations in fluid dynamics modeling with stabilized and multiscale methods. Math Models Methods Appl Sci 25:2217-2226. https://doi.org/10.1142/S0218202515020029

46. Bazilevs Y, Takizawa K, Tezduyar TE (2019) Computational analysis methods for complex unsteady flow problems. Math Models Methods Appl Sci 29:825-838. https://doi.org/10.1142/ S0218202519020020

47. Kalro V, Tezduyar TE (2000) A parallel 3D computational method for fluid-structure interactions in parachute systems. Comput Methods Appl Mech Eng 190:321-332. https://doi.org/10.1016/ S0045-7825(00)00204-8

48. Bazilevs Y, Hughes TJR (2007) Weak imposition of Dirichlet boundary conditions in fluid mechanics. Comput Fluids 36:1226

49. Bazilevs Y, Michler C, Calo VM, Hughes TJR (2010) Isogeometric variational multiscale modeling of wall-bounded turbulent flows with weakly enforced boundary conditions on unstretched meshes. Comput Methods Appl Mech Eng 199:780-790

50. Hsu M-C, Akkerman I, Bazilevs Y (2012) Wind turbine aerodynamics using ALE-VMS: validation and role of weakly enforced boundary conditions. Comput Mech 50:499-511

51. Bazilevs Y, Hughes TJR (2008) NURBS-based isogeometric analysis for the computation of flows about rotating components. Comput Mech 43:143-150

52. Hsu M-C, Bazilevs Y (2012) Fluid-structure interaction modeling of wind turbines: simulating the full machine. Comput Mech 50:821-833

53. Moghadam ME, Bazilevs Y, Hsia T-Y, Vignon-Clementel IE, Marsden AL, Modeling of Congenital Hearts Alliance (MOCHA) (2011) A comparison of outlet boundary treatments for prevention 
of backflow divergence with relevance to blood flow simulations. Comput Mech 48:277-291. https://doi.org/10.1007/s00466-0110599-0

54. Bazilevs Y, Hsu M-C, Kiendl J, Wüchner R, Bletzinger K-U (2011) 3D simulation of wind turbine rotors at full scale. Part II: Fluid-structure interaction modeling with composite blades. Int J Numer Meth Fluids 65:236-253

55. Hsu M-C, Akkerman I, Bazilevs Y (2011) High-performance computing of wind turbine aerodynamics using isogeometric analysis. Comput Fluids 49:93-100

56. Bazilevs Y, Hsu M-C, Scott MA (2012) Isogeometric fluidstructure interaction analysis with emphasis on non-matching discretizations, and with application to wind turbines. Comput Methods Appl Mech Eng 249-252:28-41

57. Hsu M-C, Akkerman I, Bazilevs Y (2014) Finite element simulation of wind turbine aerodynamics: validation study using NREL Phase VI experiment. Wind Energy 17:461-481

58. Korobenko A, Hsu M-C, Akkerman I, Tippmann J, Bazilevs Y (2013) Structural mechanics modeling and FSI simulation of wind turbines. Math Models Methods Appl Sci 23:249-272

59. Bazilevs Y, Korobenko A, Deng X, Yan J (2015) Novel structural modeling and mesh moving techniques for advanced FSI simulation of wind turbines. Int J Numer Meth Eng 102:766-783. https:// doi.org/10.1002/nme.4738

60. Korobenko A, Yan J, Gohari SMI, Sarkar S, Bazilevs Y (2017) FSI simulation of two back-to-back wind turbines in atmospheric boundary layer flow. Comput Fluids 158:167-175. https://doi.org/ 10.1016/j.compfluid.2017.05.010

61. Korobenko A, Hsu M-C, Akkerman I, Bazilevs Y (2013) Aerodynamic simulation of vertical-axis wind turbines. J Appl Mech 81:021011. https://doi.org/10.1115/1.4024415

62. Bazilevs Y, Korobenko A, Deng X, Yan J, Kinzel M, Dabiri JO (2014) FSI modeling of vertical-axis wind turbines. J Appl Mech 81:081006. https://doi.org/10.1115/1.4027466

63. Yan J, Korobenko A, Deng X, Bazilevs Y (2016) Computational free-surface fluid-structure interaction with application to floating offshore wind turbines. Comput Fluids 141:155-174. https://doi. org/10.1016/j.compfluid.2016.03.008

64. Bazilevs Y, Korobenko A, Yan J, Pal A, Gohari SMI, Sarkar S (2015) ALE-VMS formulation for stratified turbulent incompressible flows with applications. Math Models Methods Appl Sci 25:2349-2375. https://doi.org/10.1142/S0218202515400114

65. Bazilevs Y, Korobenko A, Deng X, Yan J (2016) FSI modeling for fatigue-damage prediction in full-scale wind-turbine blades. $\mathrm{J}$ Appl Mech 83(6):061010

66. Bazilevs Y, Calo VM, Zhang Y, Hughes TJR (2006) Isogeometric fluid-structure interaction analysis with applications to arterial blood flow. Comput Mech 38:310-322

67. Bazilevs Y, Gohean JR, Hughes TJR, Moser RD, Zhang Y (2009) Patient-specific isogeometric fluid-structure interaction analysis of thoracic aortic blood flow due to implantation of the Jarvik (2000) left ventricular assist device. Comput Methods Appl Mech Eng 198:3534-3550

68. Bazilevs Y, Hsu M-C, Benson D, Sankaran S, Marsden A (2009) Computational fluid-structure interaction: methods and application to a total cavopulmonary connection. Comput Mech 45:77-89

69. Bazilevs Y, Hsu M-C, Zhang Y, Wang W, Liang X, Kvamsdal T, Brekken R, Isaksen J (2010) A fully-coupled fluid-structure interaction simulation of cerebral aneurysms. Comput Mech 46:3-16

70. Bazilevs Y, Hsu M-C, Zhang Y, Wang W, Kvamsdal T, Hentschel S, Isaksen J (2010) Computational fluid-structure interaction: methods and application to cerebral aneurysms. Biomech Model Mechanobiol 9:481-498

71. Hsu M-C, Bazilevs Y (2011) Blood vessel tissue prestress modeling for vascular fluid-structure interaction simulations. Finite Elem Anal Des 47:593-599
72. Long CC, Marsden AL, Bazilevs Y (2013) Fluid-structure interaction simulation of pulsatile ventricular assist devices. Comput Mech 52:971-981. https://doi.org/10.1007/s00466-013-0858-3

73. Long CC, Esmaily-Moghadam M, Marsden AL, Bazilevs Y (2014) Computation of residence time in the simulation of pulsatile ventricular assist devices. Comput Mech 54:911-919. https://doi.org/10.1007/s00466-013-0931-y

74. Long CC, Marsden AL, Bazilevs Y (2014) Shape optimization of pulsatile ventricular assist devices using FSI to minimize thrombotic risk. Comput Mech 54:921-932. https://doi.org/10.1007/ s00466-013-0967-z

75. Hsu M-C, Kamensky D, Bazilevs Y, Sacks MS, Hughes TJR (2014) Fluid-structure interaction analysis of bioprosthetic heart valves: significance of arterial wall deformation. Comput Mech 54:1055-1071. https://doi.org/10.1007/s00466-014-1059-4

76. Hsu M-C, Kamensky D, Xu F, Kiendl J, Wang C, Wu MCH, Mineroff J, Reali A, Bazilevs Y, Sacks MS (2015) Dynamic and fluid-structure interaction simulations of bioprosthetic heart valves using parametric design with T-splines and Fung-type material models. Comput Mech 55:1211-1225. https://doi.org/ 10.1007/s00466-015-1166-x

77. Kamensky D, Hsu M-C, Schillinger D, Evans JA, Aggarwal A, Bazilevs Y, Sacks MS, Hughes TJR (2015) An immersogeometric variational framework for fluid-structure interaction: Application to bioprosthetic heart valves. Comput Methods Appl Mech Eng 284:1005-1053

78. Takizawa K, Bazilevs Y, Tezduyar TE, Hsu M-C (2019) Computational cardiovascular flow analysis with the variational multiscale methods. J Adv Eng Comput 3:366-405. https://doi.org/10. 25073/jaec.201932.245

79. Hughes TJR, Takizawa K, Bazilevs Y, Tezduyar TE, Hsu M-C (2020) Computational cardiovascular analysis with the variational multiscale methods and isogeometric discretization. In:Grama A, Sameh A (eds) Parallel algorithms in computational science and engineering, Modeling and simulation in science, engineering and technology, pp. 151-193, Springer, ISBN 978-3-030-43735-0, https://doi.org/10.1007/978-3-030-43736-7_6

80. Akkerman I, Bazilevs Y, Benson DJ, Farthing MW, Kees CE (2012) Free-surface flow and fluid-object interaction modeling with emphasis on ship hydrodynamics. J Appl Mech 79:010905

81. Akkerman I, Dunaway J, Kvandal J, Spinks J, Bazilevs Y (2012) Toward free-surface modeling of planing vessels: simulation of the Fridsma hull using ALE-VMS. Comput Mech 50:719-727

82. Wang C, Wu MCH, Xu F, Hsu M-C, Bazilevs Y (2017) Modeling of a hydraulic arresting gear using fluid-structure interaction and isogeometric analysis. Comput Fluids 142:3-14. https://doi.org/ 10.1016/j.compfluid.2015.12.004

83. Wu MCH, Kamensky D, Wang C, Herrema AJ, Xu F, Pigazzini MS, Verma A, Marsden AL, Bazilevs Y, Hsu M-C (2017) Optimizing fluid-structure interaction systems with immersogeometric analysis and surrogate modeling: Application to a hydraulic arresting gear. Comput Methods Appl Mech Eng 316:668-693

84. Yan J, Deng X, Korobenko A, Bazilevs Y (2017) Free-surface flow modeling and simulation of horizontal-axis tidal-stream turbines. Comput Fluids 158:157-166. https://doi.org/10.1016/ j.compfluid.2016.06.016

85. Augier B, Yan J, Korobenko A, Czarnowski J, Ketterman G, Bazilevs Y (2015) Experimental and numerical FSI study of compliant hydrofoils. Comput Mech 55:1079-1090. https://doi.org/ 10.1007/s00466-014-1090-5

86. Yan J, Augier B, Korobenko A, Czarnowski J, Ketterman G, Bazilevs Y (2016) FSI modeling of a propulsion system based on compliant hydrofoils in a tandem configuration. Comput Fluids 141:201-211. https://doi.org/10.1016/j.compfluid.2015.07.013

87. Helgedagsrud TA, Bazilevs Y, Mathisen KM, Oiseth OA (2019) Computational and experimental investigation of free vibration 
and flutter of bridge decks. Comput Mech. https://doi.org/10. 1007/s00466-018-1587-4

88. Helgedagsrud TA, Bazilevs Y, Korobenko A, Mathisen KM, Oiseth OA (2019) Using ALE-VMS to compute aerodynamic derivatives of bridge sections. Comput Fluids. https://doi.org/10. 1016/j.compfluid.2018.04.037

89. Helgedagsrud TA, Akkerman I, Bazilevs Y, Mathisen KM, Oiseth OA (2019) Isogeometric modeling and experimental investigation of moving-domain bridge aerodynamics. ASCE J Eng Mech 145:04019026. https://doi.org/10.1061/(ASCE)EM.19437889.0001601

90. Kamensky D, Evans JA, Hsu M-C, Bazilevs Y (2017) Projectionbased stabilization of interface Lagrange multipliers in immersogeometric fluid-thin structure interaction analysis, with application to heart valve modeling. Comput Math Appl 74:2068-2088. https://doi.org/10.1016/j.camwa.2017.07.006

91. Yu Y, Kamensky D, Hsu M-C, Lu XY, Bazilevs Y, Hughes TJR (2018) Error estimates for projection-based dynamic augmented Lagrangian boundary condition enforcement, with application to fluid-structure interaction. Math Models Methods Appl Sci 28:2457-2509. https://doi.org/10.1142/S0218202518500537

92. Tezduyar TE, Takizawa K, Moorman C, Wright S, Christopher J (2010) Space-time finite element computation of complex fluidstructure interactions. Int J Numer Meth Fluids 64:1201-1218. https://doi.org/10.1002/fld.2221

93. Yan J, Korobenko A, Tejada-Martinez AE, Golshan R, Bazilevs Y (2017) A new variational multiscale formulation for stratified incompressible turbulent flows. Comput Fluids 158:150-156. https://doi.org/10.1016/j.compfluid.2016.12.004

94. van Opstal TM, Yan J, Coley C, Evans JA, Kvamsdal T, Bazilevs Y (2017) Isogeometric divergence-conforming variational multiscale formulation of incompressible turbulent flows. Comput Methods Appl Mech Eng 316:859-879. https://doi.org/10.1016/ j.cma.2016.10.015

95. Xu F, Moutsanidis G, Kamensky D, Hsu M-C, Murugan M, Ghoshal A, Bazilevs Y (2017) Compressible flows on moving domains: stabilized methods, weakly enforced essential boundary conditions, sliding interfaces, and application to gas-turbine modeling. Comput Fluids 158:201-220. https://doi.org/10.1016/ j.compfluid.2017.02.006

96. Tezduyar TE, Takizawa K (2019) Space-time computations in practical engineering applications: a summary of the 25-year history. Comput Mech 63:747-753. https://doi.org/10.1007/s00466018-1620-7

97. Takizawa K, Tezduyar TE (2012) Computational methods for parachute fluid-structure interactions. Arch Comput Methods Eng 19:125-169. https://doi.org/10.1007/s11831-012-9070-4

98. Takizawa K, Fritze M, Montes D, Spielman T, Tezduyar TE (2012) Fluid-structure interaction modeling of ringsail parachutes with disreefing and modified geometric porosity. Comput Mech 50:835-854. https://doi.org/10.1007/s00466-012-0761-3

99. Takizawa K, Tezduyar TE, Boben J, Kostov N, Boswell C, Buscher A (2013) Fluid-structure interaction modeling of clusters of spacecraft parachutes with modified geometric porosity. Comput Mech 52:1351-1364. https://doi.org/10.1007/s00466013-0880-5

100. Takizawa K, Tezduyar TE, Boswell C, Tsutsui Y, Montel K (2015) Special methods for aerodynamic-moment calculations from parachute FSI modeling. Comput Mech 55:1059-1069. https://doi.org/10.1007/s00466-014-1074-5

101. Takizawa K, Montes D, Fritze M, McIntyre S, Boben J, Tezduyar TE (2013) Methods for FSI modeling of spacecraft parachute dynamics and cover separation. Math Models Methods Appl Sci 23:307-338. https://doi.org/10.1142/S0218202513400058

102. Takizawa K, Tezduyar TE, Boswell C, Kolesar R, Montel K (2014) FSI modeling of the reefed stages and disreefing of the Orion spacecraft parachutes. Comput Mech 54:1203-1220. https://doi. org/10.1007/s00466-014-1052-y

103. Takizawa K, Tezduyar TE, Kolesar R, Boswell C, Kanai T, Montel K (2014) Multiscale methods for gore curvature calculations from FSI modeling of spacecraft parachutes. Comput Mech 54:14611476. https://doi.org/10.1007/s00466-014-1069-2

104. Takizawa K, Tezduyar TE, Kolesar R (2015) FSI modeling of the Orion spacecraft drogue parachutes. Comput Mech 55:11671179. https://doi.org/10.1007/s00466-014-1108-z

105. Takizawa K, Henicke B, Tezduyar TE, Hsu M-C, Bazilevs Y (2011) Stabilized space-time computation of wind-turbine rotor aerodynamics. Comput Mech 48:333-344. https://doi.org/10. 1007/s00466-011-0589-2

106. Takizawa K, Henicke B, Montes D, Tezduyar TE, Hsu MC, Bazilevs Y (2011) Numerical-performance studies for the stabilized space-time computation of wind-turbine rotor aerodynamics. Comput Mech 48:647-657. https://doi.org/10.1007/ s00466-011-0614-5

107. Takizawa K, Bazilevs Y, Tezduyar TE, Hsu M-C, Øiseth O, Mathisen KM, Kostov N, McIntyre S (2014) Engineering analysis and design with ALE-VMS and space-time methods. Arch Comput Methods Eng 21:481-508. https://doi.org/10.1007/s11831014-9113-0

108. Takizawa $\mathrm{K}$ (2014) Computational engineering analysis with the new-generation space-time methods. Comput Mech 54:193-211. https://doi.org/10.1007/s00466-014-0999-z

109. Takizawa K, Henicke B, Puntel A, Kostov N, Tezduyar TE (2013) Computer modeling techniques for flapping-wing aerodynamics of a locust. Comput Fluids 85:125-134. https://doi.org/10.1016/ j.compfluid.2012.11.008

110. Takizawa K, Tezduyar TE, Kostov N (2014) Sequentially-coupled space-time FSI analysis of bio-inspired flapping-wing aerodynamics of an MAV. Comput Mech 54:213-233. https://doi.org/ 10.1007/s00466-014-0980-x

111. Takizawa K, Tezduyar TE, Buscher A, Asada S (2014) Spacetime interface-tracking with topology change (ST-TC). Comput Mech 54:955-971. https://doi.org/10.1007/s00466-013-0935-7

112. Takizawa K, Tezduyar TE, Buscher A (2015) Space-time computational analysis of MAV flapping-wing aerodynamics with wing clapping. Comput Mech 55:1131-1141. https://doi.org/10.1007/ s00466-014-1095-0

113. Takizawa K, Bazilevs Y, Tezduyar TE, Long CC, Marsden AL, Schjodt K (2014) ST and ALE-VMS methods for patientspecific cardiovascular fluid mechanics modeling. Math Models Methods Appl Sci 24:2437-2486. https://doi.org/10.1142/ S0218202514500250

114. Takizawa K, Schjodt K, Puntel A, Kostov N, Tezduyar TE (2012) Patient-specific computer modeling of blood flow in cerebral arteries with aneurysm and stent. Comput Mech 50:675-686. https://doi.org/10.1007/s00466-012-0760-4

115. Takizawa K, Schjodt K, Puntel A, Kostov N, Tezduyar TE (2013) Patient-specific computational analysis of the influence of a stent on the unsteady flow in cerebral aneurysms. Comput Mech 51:1061-1073. https://doi.org/10.1007/s00466-012-0790y

116. Suito H, Takizawa K, Huynh VQH, Sze D, Ueda T (2014) FSI analysis of the blood flow and geometrical characteristics in the thoracic aorta. Comput Mech 54:1035-1045. https://doi.org/10. 1007/s00466-014-1017-1

117. Suito H, Takizawa K, Huynh VQH, Sze D, Ueda T, Tezduyar TE (2016) A geometrical-characteristics study in patient-specific FSI analysis of blood flow in the thoracic aorta. In: Bazilevs Y, Takizawa K (eds) Advances in computational fluid-structure interaction and flow simulation: new methods and challenging computations, Modeling and simulation in science, engineering 
and technology, pp. 379-386, Springer, ISBN 978-3-319-408255, https://doi.org/10.1007/978-3-319-40827-9_29

118. Takizawa K, Tezduyar TE, Uchikawa H, Terahara T, Sasaki T, Shiozaki K, Yoshida A, Komiya K, Inoue G (2018) Aorta flow analysis and heart valve flow and structure analysis. In: Tezduyar TE (eds) Frontiers in computational fluid-structure interaction and flow simulation: research from lead investigators under Forty -2018 , Modeling and simulation in science, engineering and technology, pp. 29-89, Springer, ISBN 978-3-319-96468-3, https:// doi.org/10.1007/978-3-319-96469-0_2

119. Takizawa K, Tezduyar TE, Uchikawa H, Terahara T, Sasaki T, Yoshida A (2019) Mesh refinement influence and cardiaccycle flow periodicity in aorta flow analysis with isogeometric discretization. Comput Fluids 179:790-798. https://doi.org/10. 1016/j.compfluid.2018.05.025

120. Terahara T, Takizawa K, Tezduyar TE, Tsushima A, Shiozaki K (2020) Ventricle-valve-aorta flow analysis with the Space-Time Isogeometric Discretization and Topology Change. Comput Mech 65:1343-1363. https://doi.org/10.1007/s00466-020-01822-4

121. Takizawa K, Tezduyar TE, Buscher A, Asada S (2014) Spacetime fluid mechanics computation of heart valve models. Comput Mech 54:973-986. https://doi.org/10.1007/s00466-014-1046-9

122. Takizawa K, Tezduyar TE (2016) New directions in spacetime computational methods. In: Bazilevs Y, Takizawa K (eds) Advances in computational fluid-structure interaction and flow simulation: new methods and challenging computations, Modeling and simulation in science, engineering and technology, pp. 159-178, Springer, ISBN 978-3-319-40825-5, https://doi.org/10. 1007/978-3-319-40827-9_13

123. Takizawa K, Tezduyar TE, Terahara T, Sasaki T (2018) Heart valve flow computation with the space-time slip interface topology change (ST-SI-TC) method and isogeometric analysis (IGA). In: Wriggers P, Lenarz T (eds) Biomedical technology: modeling, experiments and simulation, Lecture notes in applied and computational mechanics, pp. 77-99, Springer, ISBN 978-3-31959547-4, https://doi.org/10.1007/978-3-319-59548-1_6

124. Takizawa K, Tezduyar TE, Terahara T, Sasaki T (2017) Heart valve flow computation with the integrated space-time VMS, slip interface, topology change and isogeometric discretization methods. Comput Fluids 158:176-188. https://doi.org/10.1016/j. compfluid.2016.11.012

125. Terahara T, Takizawa K, Tezduyar TE, Bazilevs Y, Hsu M-C (2020) Heart valve isogeometric sequentially-coupled FSI analysis with the space-time topology change method. Comput Mech 65:1167-1187. https://doi.org/10.1007/s00466-019-01813-0

126. Yu Y, Zhang YJ, Takizawa K, Tezduyar TE, Sasaki T (2020) Anatomically realistic lumen motion representation in patientspecific space-time isogeometric flow analysis of coronary arteries with time-dependent medical-image data. Comput Mech 65:395-404. https://doi.org/10.1007/s00466-019-01774-4

127. Takizawa K, Montes D, McIntyre S, Tezduyar TE (2013) Spacetime VMS methods for modeling of incompressible flows at high Reynolds numbers. Math Models Methods Appl Sci 23:223-248. https://doi.org/10.1142/s0218202513400022

128. Takizawa K, Tezduyar TE, Hattori H (2017) Computational analysis of flow-driven string dynamics in turbomachinery. Comput Fluids 142:109-117. https://doi.org/10.1016/j.compfluid.2016. 02.019

129. Komiya K, Kanai T, Otoguro Y, Kaneko M, Hirota K, Zhang Y, Takizawa K, Tezduyar TE, Nohmi M, Tsuneda T, Kawai M, Isono M (2019) Computational analysis of flow-driven string dynamics in a pump and residence time calculation. In: IOP conference series earth and environmental science 240:062014. https://doi. org/10.1088/1755-1315/240/6/062014

130. Kanai T, Takizawa K, Tezduyar TE, Komiya K, Kaneko M, Hirota K, Nohmi M, Tsuneda T, Kawai M, Isono M (2019) Methods for computation of flow-driven string dynamics in a pump and residence time. Math Models Methods Appl Sci 29:839-870. https:// doi.org/10.1142/S021820251941001X

131. Otoguro Y, Takizawa K, Tezduyar TE, Nagaoka K, Mei S (2019) Turbocharger turbine and exhaust manifold flow computation with the Space-Time Variational Multiscale Method and Isogeometric Analysis. Comput Fluids 179:764-776. https://doi.org/10.1016/ j.compfluid.2018.05.019

132. Otoguro Y, Takizawa K, Tezduyar TE, Nagaoka K, Avsar R, Zhang Y (2019) Space-time VMS flow analysis of a turbocharger turbine with isogeometric discretization: Computations with time-dependent and steady-inflow representations of the intake/exhaust cycle. Comput Mech 64:1403-1419. https://doi. org/10.1007/s00466-019-01722-2

133. Takizawa K, Tezduyar TE, Asada S, Kuraishi T (2016) Space-time method for flow computations with slip interfaces and topology changes (ST-SI-TC). Comput Fluids 141:124-134. https://doi. org/10.1016/j.compfluid.2016.05.006

134. Kuraishi T, Takizawa K, Tezduyar TE (2018) Space-time computational analysis of tire aerodynamics with actual geometry, road contact and tire deformation. In: Tezduyar TE (eds) Frontiers in computational fluid-structure interaction and flow simulation: research from lead investigators under forty - 2018, Modeling and simulation in science, engineering and technology, pp. 337-376, Springer, ISBN 978-3-319-96468-3, https://doi.org/10. 1007/978-3-319-96469-0_8

135. Kuraishi T, Takizawa K, Tezduyar TE (2019) Tire aerodynamics with actual tire geometry, road contact and tire deformation. Comput Mech 63:1165-1185. https://doi.org/10.1007/s00466018-1642-1

136. Kuraishi T, Takizawa K, Tezduyar TE (2019) Space-time computational analysis of tire aerodynamics with actual geometry, road contact, tire deformation, road roughness and fluid film. Comput Mech 64:1699-1718. https://doi.org/10.1007/s00466019-01746-8

137. Kuraishi T, Takizawa K, Tezduyar TE (2019) Space-time Isogeometric flow analysis with built-in Reynolds-equation limit. Math Models Methods Appl Sci 29:871-904. https://doi.org/10.1142/ S0218202519410021

138. Takizawa K, Tezduyar TE, Terahara T (2016) Ram-air parachute structural and fluid mechanics computations with the space-time isogeometric analysis (ST-IGA). Comput Fluids 141:191-200. https://doi.org/10.1016/j.compfluid.2016.05.027

139. Takizawa K, Tezduyar TE, Kanai T (2017) Porosity models and computational methods for compressible-flow aerodynamics of parachutes with geometric porosity. Math Models Methods Appl Sci 27:771-806. https://doi.org/10.1142/S0218202517500166

140. Kanai T, Takizawa K, Tezduyar TE, Tanaka T, Hartmann A (2019) Compressible-flow geometric-porosity modeling and spacecraft parachute computation with isogeometric discretization. Comput Mech 63:301-321. https://doi.org/10.1007/s00466-018-1595-4

141. Hsu M-C, Bazilevs Y, Calo VM, Tezduyar TE, Hughes TJR (2010) Improving stability of stabilized and multiscale formulations in flow simulations at small time steps. Comput Methods Appl Mech Eng 199:828-840. https://doi.org/10.1016/j.cma.2009.06.019

142. Takizawa K, Tezduyar TE, Otoguro Y (2018) Stabilization and discontinuity-capturing parameters for space-time flow computations with finite element and isogeometric discretizations. Comput Mech 62:1169-1186. https://doi.org/10.1007/s00466-018-1557$\mathrm{x}$

143. Takizawa K, Ueda Y, Tezduyar TE (2019) A node-numberinginvariant directional length scale for simplex elements. Math Models Methods Appl Sci 29:2719-2753. https://doi.org/10. 1142/S0218202519500581

144. Otoguro Y, Takizawa K, Tezduyar TE (2020) Element length calculation in B-spline meshes for complex geometries. Com- 
put Mech 65:1085-1103. https://doi.org/10.1007/s00466-01901809-w

145. Ueda Y, Otoguro Y, Takizawa K, Tezduyar TE (2020) Elementsplitting-invariant local-length-scale calculation in B-spline meshes for complex geometries. Math Models Methods Appl Sci. https://doi.org/10.1142/S0218202520500402

146. Corsini A, Menichini C, Rispoli F, Santoriello A, Tezduyar TE (2009) A multiscale finite element formulation with discontinuity capturing for turbulence models with dominant reactionlike terms. J Appl Mech 76:021211. https://doi.org/10.1115/1.3062967

147. Rispoli F, Saavedra R, Menichini F, Tezduyar TE (2009) Computation of inviscid supersonic flows around cylinders and spheres with the V-SGS stabilization and YZ $\beta$ shock-capturing. J Appl Mech 76:021209. https://doi.org/10.1115/1.3057496

148. Corsini A, Iossa C, Rispoli F, Tezduyar TE (2010) A DRD finite element formulation for computing turbulent reacting flows in gas turbine combustors. Comput Mech 46:159-167. https://doi.org/ 10.1007/s00466-009-0441-0

149. Corsini A, Rispoli F, Tezduyar TE (2011) Stabilized finite element computation of NOx emission in aero-engine combustors. Int J Numer Meth Fluids 65:254-270. https://doi.org/10.1002/fld. 2451

150. Corsini A, Rispoli F, Tezduyar TE (2012) Computer modeling of wave-energy air turbines with the SUPG/PSPG formulation and discontinuity-capturing technique. J Appl Mech 79:010910. https://doi.org/10.1115/1.4005060

151. Kler PA, Dalcin LD, Paz RR, Tezduyar TE (2013) SUPG and discontinuity-capturing methods for coupled fluid mechanics and electrochemical transport problems. Comput Mech 51:171-185. https://doi.org/10.1007/s00466-012-0712-Z

152. Rispoli F, Delibra G, Venturini P, Corsini A, Saavedra R, Tezduyar TE (2015) Particle tracking and particle-shock interaction in compressible-flow computations with the V-SGS stabilization and $\mathrm{YZ} \beta$ shock-capturing. Comput Mech 55:1201-1209. https:// doi.org/10.1007/s00466-015-1160-3

153. Castorrini A, Venturini P, Corsini A, Rispoli F, Takizawa K, Tezduyar TE (2020) Computational analysis of particle-laden-airflow erosion and experimental verification. Comput Mech 65:15491565. https://doi.org/10.1007/s00466-020-01834-0

154. Tezduyar TE, Aliabadi SK, Behr M, Mittal S (1994) Massively parallel finite element simulation of compressible and incompressible flows. Comput Methods Appl Mech Eng 119:157-177. https://doi.org/10.1016/0045-7825(94)00082-4

155. Hughes TJR, Cottrell JA, Bazilevs Y (2005) Isogeometric analysis: CAD, finite elements, NURBS, exact geometry, and mesh refinement. Comput Methods Appl Mech Eng 194:4135-4195

156. Takizawa K, Tezduyar TE (2014) Space-time computation techniques with continuous representation in time (ST-C). Comput Mech 53:91-99. https://doi.org/10.1007/s00466-013-0895-y

157. Tezduyar TE, Cragin T, Sathe S, Nanna B (2007) FSI computations in arterial fluid mechanics with estimated zero-pressure arterial geometry. In: Onate E, Garcia J, Bergan P, Kvamsdal T (eds) Marine 2007. CIMNE, Barcelona

158. Tezduyar TE, Sathe S, Schwaab M, Conklin BS (2008) Arterial fluid mechanics modeling with the stabilized space-time fluidstructure interaction technique. Int J Numer Meth Fluids 57:601629. https://doi.org/10.1002/fld.1633

159. Takizawa K, Christopher J, Tezduyar TE, Sathe S (2010) Spacetime finite element computation of arterial fluid-structure interactions with patient-specific data. Int J Numer Methods Biomed Eng 26:101-116. https://doi.org/10.1002/cnm.1241

160. Takizawa K, Moorman C, Wright S, Purdue J, McPhail T, Chen PR, Warren J, Tezduyar TE (2011) Patient-specific arterial fluidstructure interaction modeling of cerebral aneurysms. Int J Numer Meth Fluids 65:308-323. https://doi.org/10.1002/fld.2360
161. Tezduyar TE, Takizawa K, Brummer T, Chen PR (2011) Spacetime fluid-structure interaction modeling of patient-specific cerebral aneurysms. Int J Numer Methods Biomed Eng 27:1665-1710. https://doi.org/10.1002/cnm.1433

162. Takizawa K, Takagi H, Tezduyar TE, Torii R (2014) Estimation of element-based zero-stress state for arterial FSI computations. Comput Mech 54:895-910. https://doi.org/10.1007/s00466-0130919-7

163. Takizawa K, Torii R, Takagi H, Tezduyar TE, Xu XY (2014) Coronary arterial dynamics computation with medical-image-based time-dependent anatomical models and element-based zero-stress state estimates. Comput Mech 54:1047-1053. https://doi.org/10. 1007/s00466-014-1049-6

164. Takizawa K, Tezduyar TE, Sasaki T (2018) Estimation of elementbased zero-stress state in arterial FSI computations with isogeometric wall discretization. In: Wriggers P, Lenarz T (eds) Biomedical technology: modeling, experiments and simulation, Lecture notes in applied and computational mechanics, pp. 101-122, Springer, ISBN 978-3-319-59547-4, https://doi.org/10. 1007/978-3-319-59548-1_7

165. Takizawa K, Tezduyar TE, Sasaki T (2017) Aorta modeling with the element-based zero-stress state and isogeometric discretization. Comput Mech 59:265-280. https://doi.org/10.1007/s00466016-1344-5

166. Sasaki T, Takizawa K, Tezduyar TE (2019) Aorta zero-stress state modeling with T-spline discretization. Comput Mech 63:13151331. https://doi.org/10.1007/s00466-018-1651-0

167. Sasaki T, Takizawa K, Tezduyar TE (2019) Medical-image-based aorta modeling with zero-stress-state estimation. Comput Mech 64:249-271. https://doi.org/10.1007/s00466-019-01669-4

168. Takizawa K, Tezduyar TE, Sasaki T (2019) Isogeometric hyperelastic shell analysis with out-of-plane deformation mapping. Comput Mech 63:681-700. https://doi.org/10.1007/s00466-0181616-3

169. Bazilevs Y, Hsu M-C, Kiendl J, Benson DJ (2012) A computational procedure for pre-bending of wind turbine blades. Int $\mathrm{J}$ Numer Meth Eng 89:323-336

170. Bazilevs Y, Deng X, Korobenko A, di Scalea FL, Todd MD, Taylor SG (2015) Isogeometric fatigue damage prediction in large-scale composite structures driven by dynamic sensor data. J Appl Mech 82:091008

171. Herrema AJ, Johnson EL, Proserpio D, Wu MCH, Kiendl J, Hsu M-C (2019) Penalty coupling of non-matching isogeometric Kirchhoff-Love shell patches with application to composite wind turbine blades. Comput Methods Appl Mech Eng 346:810-840

172. Herrema AJ, Kiendl J, Hsu M-C (2019) A framework for isogeometric-analysis-based optimization of wind turbine blade structures. Wind Energy 22:153-170

173. Johnson EL, Hsu M-C (2020) Isogeometric analysis of ice accretion on wind turbine blades. Comput Mech 66:311-322

Publisher's Note Springer Nature remains neutral with regard to jurisdictional claims in published maps and institutional affiliations. 